\title{
The Development of Infant Intersensory Perception: Advantages of a Comparative Convergent-Operations Approach
}

\author{
Robert Lickliter \\ Virginia Polytechnic Institute and State University
}

\author{
Lorraine E. Bahrick \\ Florida International University
}

\begin{abstract}
Despite impressive demonstrations of human infants' intersensory capabilities over the past several decades, there has been little focus on the contributions of prenatal and postnatal experience or the specific developmental processes underlying the emergence of intersensory functioning. Research with nonhuman animals has, however, provided a number of advances in understanding early intersensory perception. The authors explore the value of a comparative, convergent-operations approach to the study of early intersensory perception and examine how this approach has highlighted the study of (a) prenatal factors, (b) brain-behavior relations, and (c) context and experience variables contributing to infants' intersensory responsiveness. Examples of how human and animal research programs can cross-fertilize one another in their attempts to understand developmental processes underlying intersensory perception are considered.
\end{abstract}

After all, it is only by comparing that we can judge, for our knowledge rests entirely on the relations that things have with others that are similar or different, and we should realize that if there were no animals, the nature of man would be even more incomprehensible.

-G. L. Buffon, Historie Naturelle

Most objects and events in the world provide multimodal stimulation and evoke a diversity of visual, auditory, tactile, and olfactory impressions simultaneously. How does the young infant determine which patterns of sensory stimulation belong together and originate from a single object or event and which are unrelated? What causes some stimulation to be salient, attended, processed further, and remembered, and other stimulation to be ignored by infants? Although developmental science is far from conclusively answering these important questions, there has been an increasing research focus on the study of the intermodal capabilities of human infants over the past several decades (see, e.g., Aslin \& Smith, 1988; Lewkowicz \& Lickliter, 1994a; McKenzie \& Day, 1987; Meltzoff, 1990; Rose \& Ruff, 1987; Spelke, 1984). This research has been largely descriptive and has primarily been directed at establishing the nature of various perceptual competencies over the course of the first year following birth. This body of work has established that young infants are far from being passive

Robert Lickliter, Department of Psychology, Virginia Polytechnic Institute and State University; Lorraine E. Bahrick, Department of Psychology, Florida International University.

The writing of this article was supported by National Institute of Mental Health Grants RO1 MH48949 and KO2 MH01210 and National Institute of Child Health and Human Development Grant RO1 HD25669.

We thank Gilbert Gottlieb, David Lewkowicz, and Gerald Turkewitz for their constructive comments.

Correspondence concerning this article should be addressed to Robert Lickliter, Department of Psychology, Virginia Polytechnic Institute and State University, Blacksburg, Virginia 24061. Electronic mail may be sent to duckling@vt.edu. or disorganized perceivers; rather, infants have been shown to be active, organized, and competent explorers of the self and the environment.

For example, research in this area has documented that young infants can display a large and diverse repertoire of intersensory abilities, including the ability to match faces and voices on the basis of voice-lip synchrony (Dodd, 1979), speech sounds (Kuhl \& Meltzoff, 1984), affective expressions (Walker-Andrews, 1986, 1997), and age and gender of the speaker (Bahrick, Netto, \& Hernandez-Reif, 1998; Walker-Andrews, Bahrick, Raglioni, \& Diaz, 1991). Infants have also been shown to be sensitive to a number of temporal parameters unifying auditory and visual stimulation in the months following birth, including synchrony (Bahrick, 1987, 1988, 1992; Lewkowicz, 1986, 1992, 1996b; Spelke, 1981), rate (Lewkowicz, 1985; Spelke, 1979), rhythm (Allen, Walker, Symonds, \& Marcell, 1977; Bahrick \& Lickliter, in press; Mendelson \& Ferland, 1982), and duration (Lewkowicz, 1986). Related work has also demonstrated impressive haptic-visual connections during early development, including tactile discrimination and cross-modal transfer abilities within the first months of postnatal life (Bushnell, 1982; Clifton, Rochat, Robin, \& Bertheir, 1994; Meltzoff \& Borton, 1979; Rochat \& Senders, 1991; Rose, 1994; Streri, 1993; Streri \& Molina, 1994; Streri \& Pecheux, 1986).

Despite these impressive demonstrations of human infants' intersensory capabilities, there has been limited concern in this body of work for the possible contributions of prior prenatal and postnatal experience or for the specific developmental processes underlying the emergence and maintenance of intersensory functioning. The field of infant perceptual development has historically focused on demonstrating the age at which babies manifest particular perceptual skills (see Haith, 1993; Rose \& Ruff, 1987) and has only recently begun to focus on the developmental background underlying how such perceptual skills are achieved (Lewkowicz \& Lickliter, 1994a). This emphasis on what and when, rather than 
how, has been guided in large part by the important task of establishing the nature of early capacities and their developmental course during the first postnatal year. As a result of this emphasis, however, relatively little is currently known regarding the specific roles of infants' arousal, attention, and previous experience, or the roles of context and social interaction in the development of early intersensory functioning.

This state of affairs is no doubt due in large part to the inherent limitations of working with human infants. Experiential manipulations of human fetuses and neonates are necessarily limited in scope and duration, and traditional experimental manipulations used with animal subjects such as sensory deprivation or sensory augmentation are generally not possible. However, during the last several decades, the topic of intersensory perception has also received increasing research attention from both developmental biologists and psychobiologists working with nonhuman animals (see, e.g., Alberts, 1984; Gottlieb, 1971, 1993; Knudsen \& Brainard, 1995; Lickliter, 1995; Lickliter \& Banker, 1994; Radell \& Gottlieb, 1992; Spear, 1984; Stein \& Meredith, 1993; Tees, 1994; Turkewitz \& Kenny, 1982). This body of work has taken advantage of the benefits that animals provide for developmental research, including precise experiential control and the opportunity to supplement behavioral measures with neurophysiological manipulations and measures. This animal literature has provided a number of advances in researchers' understanding of the emergence of intersensory capacities, including the importance of the timing of presentation of sensory stimulation during perinatal development (Kenny \& Turkewitz, 1986; Lickliter, 1990, 1993; Sleigh \& Lickliter, 1998; Spear \& McKinzie, 1994), the influence of early social interaction on perceptual organization (Columbus \& Lickliter, 1998; Gottlieb, 1991b, 1993; Lickliter, Dyer, \& McBride, 1993; McBride \& Lickliter, 1993), and the strong intermodal linkages of the sensory modalities during perinatal development (Gottlieb, Tomlinson, \& Radell, 1989; Lickliter \& Lewkowicz, 1995; Lickliter \& Stoumbos, 1991; Radell \& Gottlieb, 1992), to name but a few recent examples.

Curiously, such discoveries and insights regarding the development of intersensory perception drawn from the comparative literature have rarely been integrated into efforts to understand human infant intersensory perception. In a review of the study of infant perceptual development, Haith (1993) concluded that the exploration of human infant sensory and perceptual processes is a field unto itself, with little attempt being made to unite theory, concepts, and methods used for studying infancy with those used for studying older children, adults, or other animal species. This certainly seems to be the case in the area of intermodal perception, despite the fact that animal-based research could provide useful guidelines for asking questions about the structure and function of human behavior and that human findings could likewise serve to direct the scope and focus of experiments with animal embryos, fetuses, and infants that are not available for research on human behavior. The current lack of integration between developmental and comparative psychology is difficult to understand, particularly in light of the fact that advances in comparative anatomy, embryology, and physiology have contributed to significant advances in our understanding of human biology and medical science (see Alter, Hartgraves, \& Wayner, 1991, for a review). As a case in point, veterinarian-physician partnerships are becoming increasingly common in recent years, with investigators from human and veterinary medicine often finding their research paths intersecting to solve medical issues that might have continued to baffle them individually:

Of course, developmentalists cannot answer questions about human development by primarily studying animals, but we believe that comparative work can provide new questions and methods and can potentially identify general developmental principles that could be tested with humans. As recently argued by Arnold and Spear (1997), the determinants of the ontogeny of behavior, including perception, are too basic to consider them unique to humans. The utilization of interdisciplinary, comparative, and convergent research strategies seems an important step in discovering and defining the various conditions, experiences, and events (both internal and external to the organism) necessary and sufficient to support the emergence and maintenance of normal perceptual development. As pointed out by a number of psychologists over the past 30 years, comparative and convergent research can significantly inform theories of human behavior not only in cases where similarities are found but also in cases where differences in the mechanisms underlying behavior are found (see Ettlinger \& Wilson, 1990; Fleischer \& Turkewitz, 1984; Overmier \& Burke, 1992; Schneirla, 1966). This type of approach is in keeping with the vision of the pioneering developmentist Zing-Yang Kuo (1967, 1970), who promoted the need for coordinated efforts in developmental studies over 3 decades ago. He argued that because behavioral development is such a complex and complicated process, no single branch of psychology or biology can adequately address its study on an appropriately comprehensive scale.

Given the explosion of data from the biological and behavioral sciences over the past 25 years, the application of a convergentoperations approach seems even more necessary and appropriate than when Kuo highlighted its value. We define a convergentoperations approach as the cooperation and coordination across varied disciplines, levels of analysis, methods, and independent laboratories to provide a broader and deeper perspective to developmental issues. By generating findings from multiple levels of analysis and from multiple species and converging on patterns of similarity as well as differences across levels and species, a convergent-operations approach can foster a broader perspective to basic research issues than more traditional, species-specific approaches and is more likely to generate principles of perceptual development that are fundamental and generalizable across species and across populations (for a different use of the term converging operations in the study of perceptual development, see Proffitt \& Bertenthal, 1990). This is an important task of developmental science, as the specific processes underlying normal perceptual development remain largely unknown or unexplored for most species, including humans. In this article, we explore the value of a comparative, convergent-operations approach to the study of early intersensory perception. We examine how a comparative approach has allowed for the empirical study of (a) prenatal factors, (b) brain-behavior relationships, and (c) context and experience variables thought to be involved in the development of early intersensory perception. In addition, we briefly consider examples of how work from human and animal research programs can cross-fertilize one another in their attempts to explain the developmental processes underlying the emergence of intersensory perception. It is important to stress that this article is not intended as a comprehensive review of the field of infant perceptual devel- 
opment (for such a review, see Kellman \& Arterberry, 1998) nor does it provide a detailed catalog of infants' intersensory capacities at different ages (see Rose \& Ruff, 1987). Rather, our principal goal is to explore how the application of a comparative, convergent-operations perspective can provide students of early perceptual development with a framework that is biologically plausible, acknowledges the complex and dynamic nature of development, and integrates developmental data from multiple levels of analysis.

It is also important to emphasize that we are not suggesting that other animal species simply be used as a model for the study of human behavior (see Fleischer \& Turkewitz, 1984; Staddon, 1989). Rather, we argue that the study of a wide range of organisms allows for the comparison of similarities and differences that can be highly informative for a deeper understanding of the development of intersensory perception. In other words, our rationale for including a more explicit focus on animal-oriented research in developmental psychology is not to provide stand-in models for the study of human development. Rather, we propose that comparative work can provide simpler and more experimentally accessible systems that can be probed to begin to identify and define general themes or principles of development (see also Hofer, 1987; Smotherman \& Robinson, 1995). Although comparative research with animal subjects has been critical in experimentally addressing issues that are of fundamental importance to psychological science, including sensation and perception, learning and motivation, memory, psychopatholgy, and the relationship between stress and disease (Domjan \& Purdy, 1995), we find that comparative research has not been well integrated into contemporary developmental theory concerned with perceptual development. A brief review of the conceptual frameworks guiding most theory and research in the area of human infant intersensory development over the past 30 years serves to make this point.

\section{Traditional Approaches to the Development of Intersensory Perception}

Two prevailing theoretical views, known respectively as the integration view and the differentiation view, have dominated the study of intersensory development until recent years (see Bahrick \& Pickens, 1994; Lewkowicz, 1994, for brief reviews). In a general sense, the integration view holds that the different sensory modalities function as separate sensory systems during the initial stages of postnatal development and become integrated during development through the infant's activity and repeated experience with concurrent information provided by the different sensory modalities (Birch \& Lefford, 1963, 1967; Friedes, 1974; Piaget, 1952). In contrast, the differentiation view holds that the different senses form a primitive unity early in development and, as the infant develops, the modalities differentiate from one another and the information arising from the different sensory modalities becomes further differentiated as well. From this view, infants are thought to differentiate finer and more complex multimodal relations through their experience over the course of development (Bahrick, in press; Bower, 1974; E. J. Gibson, 1969; J. J. Gibson, 1966; Marks, 1978). As a result of these opposing views, the most prominent questions guiding research on early intersensory development over the past several decades have tended to focus on (a) whether intersensory development proceeds from initially separate senses that become increasingly integrated through experience, eventually resulting in coordinated multimodal perception, or (b) whether the development of intersensory perception is a process of differentiation and increasing specificity (Bahrick, in press; Lewkowicz \& Lickliter, 1994a; Rose \& Ruff, 1987).

Although some controversy remains as to whether perceptual development proceeds from a wholistic unity to differentiated sensory modalities or from separated senses to coordinated multimodal experience (Bushnell, 1994; Kellman \& Arterberry, 1998; Maurer, 1993), the dominant view at present argues against what now appears to be an artificial dichotomy between integration and differentiation views of perceptual development. Increasing focus on infant intersensory perception over the past several decades has provided mounting evidence that both processes are likely involved in perceptual development. On the one hand, there is now compelling neuroanatomical, neurophysiological, and behavioral evidence of strong intermodal linkages in newborns and young infants from a variety of species, including humans (Carlsen \& Lickliter, 1999; Lewkowicz \& Turkewitz, 1980; Lickliter, 1993; Maurer, 1993; Mellon, Kraemer, \& Spear, 1991; Stein \& Meredith, 1993). Infant animals are more likely to show sensitivity to intersensory correspondences than are older animals in a classicalconditioning learning paradigm (Spear \& McKinzie, 1994), and human infants demonstrate an array of intermodal perceptual skills in the weeks and months following birth, including intersensory facilitation, in which stimulation in one modality enhances responsiveness to stimuli in other modalities (Lewkowitz \& Lickliter, 1994a; Morrongiello, Fenwick, \& Chance, 1998; Turkewitz \& Mellon, 1989).

In addition, young infants have been shown to be skilled perceivers of amodal information (Bahrick, 1988, 1992; Bahrick \& Lickliter, in press; Bahrick \& Pickens, 1994; Spelke, 1979; Walker-Andrews, 1986), that is, information that is not specific to a particular sensory modality but is redundant across two or more modalities. For example, the sights and sounds of hands clapping share temporal synchrony, a common tempo of action, and a common rhythm. The amodal properties of synchrony, tempo, and rhythm are concurrently available both visually and acoustically. Given that the role of integration is presumably to link together separate sensations to form a unified percept, in the common cases where redundant information is obtained by two or more perceptual systems, infants' detection and abstraction of amodal relations makes the need for intersensory integration unlikely. It seems more congruent with available evidence to characterize young infants as adept perceivers of amodal information (based on a process of differentiation) than to conclude that detection of amodal relations depends on a process of association or integration across different modalities.

On the other hand, infants can also detect perceptual information that is not amodal in the months following birth. For example, infants clearly become more skilled at detecting intersensory relations that are modality-specific or arbitrary in nature over the course of the first year of life (Bahrick, 1994, in press; Bushnell, 1994). Many relations between stimulus properties conveyed concurrently to different modalities are arbitrary in the sense that they are not united by information common across the different sensory modalities and can vary as a function of context or stimulus domain. For example, the relation between the appearance of an object and the verbal label given it, or that between a person's 
appearance and the specific sound of his or her voice, or that between the type of sound a particular toy produces and its color and shape are cases of arbitrary pairings of stimulation across to two or more sensory modalities. Given that there is no common information that links the stimulation presented to the two or more modalities, such arbitrary relations must be learned by experiencing the information in the modalities together and may thus be characterized as depending on some process of integration.

In sum, it appears that both integrative and differentiating processes are involved in the emergence and maintenance of various types of intersensory functioning. The recognition of the important role of these parallel processes and their interaction has led several investigators, including Botuck and Turkewitz (1990), Lewkowicz and Lickliter (1994b), Smith (1994), Thelen and Smith (1994), and Werner (1957), to suggest that integration and differentiation processes are best considered complementary rather than mutually exclusive. In this light, recent research is beginning to unravel how the processes of differentiating amodal relations and integrating arbitrary or modality-specific information across the senses can interact with one another in certain domains or in the development of certain skills. For example, a growing body of evidence suggests that young infants' detection of amodal relations developmentally precedes and can provide an initial basis for detecting arbitrary relations (Bahrick, 1992, 1994, in press; Gogate \& Bahrick, 1998; Slater, in press). In particular, the detection of amodal relations appears to specify the unity of multimodal stimulation, to capture and direct infant attention, and to facilitate the further differentiation of a coordinated multimodal percept (Bahrick \& Lickliter, in press; Bahrick \& Pickens, 1994). Such detection can guide and constrain detection of other nested intersensory relations, including arbitrary relations.

As a case in point, 7-month-old infants have been shown capable of learning the arbitrary relation between an object and a speech sound but only when the object was moved in temporal synchrony with the sound. When the object was still or moved asynchronously with the speech sound, 7-month-olds showed no evidence of linking the speech sound and the object (Gogate \& Bahrick, 1998). In this example, learning of arbitrary relations appeared to be (at least initially) guided and facilitated by the detection of amodal relations present in multimodal stimulation. Related research has also shown a developmental lag between the detection of amodal and arbitrary relations in a given domain. By 3 months of age, infants viewing objects striking a surface were capable of detecting the amodal properties of temporal synchrony and the temporal microstructure specifying an object's composition. However, not until 7 months of age did infants demonstrate the detection of the arbitrary relation between the pitch of the impact sound and the appearance of the objects (Bahrick, 1992, 1994, in press). Such findings suggest that amodal properties of objects and events are perceived earlier and more readily than are relationships between modality-specific properties.

Although the interaction between differentiation and integration and their complementary roles in the emergence and maintenance of intersensory functioning are clearly research topics worthy of more systematic investigation, we do not believe that a conceptual shift away from the traditional either/or perspective will in and of itself prove adequate in forging a more complete and coherent view of early intersensory perception. For example, both views have tended to undercharacterize the complex and dynamic pro- cesses of organization and reorganization occurring within and between sensory systems documented in the study of animal infants' prenatal and postnatal development (Banker \& Lickliter, 1993; Freeman, 1991; Kenny \& Turkewitz, 1986; Lickliter \& Lewkowicz, 1995; Radell \& Gottlieb, 1992; Symons \& Tees, 1990). More specifically, the integration and differentiation perspectives of early human development have held several common (and often implicit) underlying assumptions that can be called into question in light of comparative work concerned with intersensory development.

\section{Challenges to Traditional Views of Intersensory} Development: Insights From Comparative Psychology

An implicit assumption of both the integration and differentiation viewpoints on perceptual development has been that the sensory systems start out at birth on an essentially equal basis. This assumption stands in contrast to results from the comparative literature regarding the neuroembryological development of the sensory systems. The various sensory modalities of birds and mammals (including humans) do not become functional at the same time in development. Rather, the sensory systems become functional in an invariant and relatively universal sequence: tactile $\rightarrow$ vestibular $\rightarrow$ chemical $\rightarrow$ auditory $\rightarrow$ visual (Alberts, 1984; Bradley \& Mistretta, 1975; Gottlieb, 1971). As a result, the various individual sensory modalities have had different developmental histories during the prenatal and early postnatal periods.

The fact that the sensory systems of birds and mammals do not become functional at the same time in early development raises the question of how sensory systems and their different stimulation histories influence one another during the perinatal period. Work with a variety of animal infants has provided collective evidence that experiential differences between the sensory systems can significantly affect the ability of a particular modality to process a given type of sensory input at a given point in early development (Gottlieb, 1971; Kenny \& Turkewitz, 1986; Lickliter, 1993; Lickliter \& Banker, 1994; Turkewitz \& Kenny, 1982, 1985). The successive emergence of sensory system function also appears to affect the salience of various types of sensory information (Lickliter, 1994), as well as influencing young infants' selective attention to specific sensory information during the perinatal period (Gottlieb, Tomlinson, \& Radell, 1989; Lickliter \& Hellewell, 1992; Spear \& McKinzie, 1994).

As a case in point, responsiveness to auditory information (which becomes functional prenatally in precocial animal infants, including humans) has been shown to have initial priority over responsiveness to visual information during the early stages of the postnatal period in several precocial animal species (i.e., chickens and ducks, Gottlieb \& Simner, 1969; Johnston \& Gottlieb, 1981; quail, Lickliter \& Virkar, 1989; sheep, Shillito, 1975). This early sensory salience hierarchy is due, at least in part, to the fact that at the time of birth, the auditory and visual systems have had dramatically different amounts of prenatal experience (Lickliter, 1994). Work with human infants, whether driven by the integration or the differentiation view, has typically not considered the possible influences of such timing or asynchronicity issues in accounting for intersensory capacity (but see Lewkowicz, 1988a, 1988b). In particular, the dynamic nature of the relationship between the state of development of already functioning sensory systems and 
the introduction of input from newly emerging systems is poorly understood for human infants. For example, the emergence of visual functioning and the increasingly multimodal nature of sensory stimulation following birth signal a potentially major shift in the newborn's experiential milieu, but relatively little is known about the attentional, sensory, motor, and social factors associated with this shift. Recent research with both animal and human infants suggests that different properties of stimuli are highlighted and attended to as concurrent and redundant multimodal stimuli are made.increasingly available to the young organism (Bahrick, in press; Bahrick \& Lickliter, in press; Sleigh, Columbus, \& Lickliter, 1998). From an applied perspective, this is an area that would benefit from more research attention, as preterm infants are routinely subjected to patterned light at an age when they would not normally be exposed to such visual stimulation. The intra- and intermodal consequences of such unusually early visual experience are only beginning to be examined (Als, 1995; Marshall-Baker, Lickliter, \& Cooper, 1998; Mueller, 1996).

A second underlying assumption common to both the integration and differentiation views of perceptual development is that intersensory functioning is a unitary phenomenon that can be characterized by a single developmental pathway (i.e., from initially separate senses to coordinated multimodal experience or from initial unity of the senses to differentiated modalities). However, as originally noted by Ryan (1940) and articulated more recently by Turkewitz and his colleagues (Botuck \& Turkewitz, 1990; Turkewitz \& McGuire, 1978; Turkewitz \& Mellon, 1989), there are a number of different types or categories of intersensory functioning, including intersensory inhibition and facilitation, intersensory equivalence, and multimodal coordination (see also Walker-Andrews, 1994). There is no reason to necessarily assume that these different instances of intersensory functioning share common developmental processes or pathways. Indeed, work from the comparative literature suggests that different categories of intersensory functioning may have their own developmental trajectories and may be influenced by different neural, physiological, psychological, and/or social factors (Stein \& Meredith, 1993; Tees, 1994; Turkewitz, 1994).

For example, studies with precocial animal infants have found intersensory inhibition and facilitation to be sensitive to such stimulus characteristics as the overall amount and the specific type of stimulation presented to the various sensory modalities (Gottlieb, Tomlinson, \& Radell, 1989; Lickliter \& Lewkowicz, 1995; Radell \& Gottlieb, 1992; Sleigh \& Lickliter, 1996), as well as to organismic characteristics such as the stage of developmental organization and the state of arousal of the embryo or infant (Gottlieb, 1993; Kenny \& Turkewitz, 1986; Sleigh \& Lickliter, 1997). In contrast, whereas the capacity to perceive intersensory equivalence is also sensitive to the organism's stage of development (Spear \& McKinzie, 1994), such capacity appears to be largely dependent on the relative intensity of sensory stimulation, an amodal attribute that appears to have special significance for animal and human infants in the period immediately following birth (Lewkowicz, 1991; Lewkowicz \& Turkewitz, 1980, 1981; Schneirla, 1959; Spear, Kraemer, Molina, \& Smoller, 1988; Turkewitz, Lewkowicz, \& Gardner, 1983).

\section{Emerging Themes of Early Perceptual Development}

The several challenges to underlying assumptions associated with the integration and differentiation views of human infant perception briefly reviewed above serve to illustrate that a fuller integration of results from comparative work into developmental psychology could both expand researchers' thinking about the possible processes and mechanisms underlying early perceptual organization and allow the examination of existing premises and hypotheses against a wider range of data. In this light, the questions of how the individual sensory modalities relate to one another and how their functions are tied to the experiential history of the organism have been a growing concern to investigators working in developmental biology, psychobiology, and the neurosciences. The collective findings from this body of comparative-based research have allowed the identification of several general themes or principles regarding the process of early perceptual development that are gradually being incorporated into the study of human development. These themes include the following.

(1) Perceptual development is activity dependent. That is, the young organism's skills and capabilities emerge from its ongoing activities and encounters with its developmental milieu.

(2) Perceptual development is context sensitive. Developmental outcomes are strongly influenced or modified by the particular features of the young organism's physical and social surround.

(3) Perceptual skills and abilities are multidetermined; they emerge from the relationship between factors internal and external to the organism. No level or component (be it internal or external to the infant) necessarily has causal priority in controlling or directing perceptual development.

(4) Intersensory linkages and interactions are common during both prenatal and early postnatal periods. Shifts or alterations in experience in one sensory modality can influence subsequent perceptual functioning not only in that modality but in other sensory modalities as well.

(5) Embryos, fetuses, and newborns are particularly sensitive to the overall amount of available sensory stimulation. Substantial increases or decreases in the range (amount and type) of sensory stimulation available to young organisms can result in significant alterations in or interference with normal patterns of perceptual functioning.

(6) Infants have a long history of sensory experience prior to birth, and this history influences postnatal perceptual organization. Rather than being innate or somehow built in, skills or capabilities seen at birth or shortly thereafter are the result, at least in part, of prior prenatal conditions and experiences.

These related themes are particularly evident in comparative developmental research concerned with (a) prenatal factors, (b) brain-behavior relationships, and (c) context and experiential variables thought to be involved in early intersensory functioning. A brief overview of these topics highlights the potential value and applicability of these general themes to the study of human perceptual development.

\section{Prenatal Processes Underlying Intersensory Functioning}

A growing interest in the psychobiological development of the human fetus has emerged in the past several decades (Lecanuet, Fifer, Krasnegor, \& Smotherman, 1995; Smotherman \& Robinson, 
1988). This interest has capitalized on advances and innovations in medical technology, particularly ultrasonography, and has allowed detailed description of the fetus and its behavior in real time (James, Pillai, \& Smoleniec, 1995; Nijhuis, Martin, \& Prechtl, 1984). As a result, substantial insights are being made into the various regulatory processes thought to underlie the emergence of fetal capacities during the prenatal period (Gagnon, 1995; Robertson \& Bacher, 1995). However, systematic manipulation of the human fetus's behavioral and neural systems during the prenatal period is generally prohibited, and the use of such experimental methods is possible only with nonhuman animal subjects. Thus, the study of prenatal development is an obvious forum for the cross-fertilization of animal- and human-based research programs (Lecanuet, Fifer, Krasnegor, \& Smotherman, 1995). For example, although human fetal activity is clearly organized and demonstrates developmental changes in its patterns, the causes of this activity or its consequences remain largely unknown. A shift in focus from what and when questions about prenatal development to how questions is clearly in the making and can benefit from knowledge derived from research on other animal species. In particular, links between animal and human research can allow the empirical examination of the continuities and discontinuities between prenatal and postnatal functioning (see, e.g., Marlier, Schaal, \& Soussignan, 1997, 1998; Schaal, Orgeur, \& Arnould, 1995) not easily addressed in human studies alone.

One obvious advantage of the use of animal subjects to study perceptual development in the prenatal period is the ability to readily alter both the timing and amount of particular sensory experience available to the developing embryo or fetus. Comparative studies employing sensory deprivation or sensory augmentation during the perinatal period have yielded information regarding the experiential conditions necessary for the normal development of intersensory perception in both altricial and precocial animal infants (Foreman \& Altaha, 1991; Gottlieb, 1971, 1976, 1997; Kenny \& Turkewitz, 1986; Lickliter, 1990, 1993, 1995; Tees \& Symons, 1987). In a general sense, this body of research serves to illustrate the theme that normally occurring sensory experience during the prenatal period actively shapes the development of species-specific perceptual capabilities. More specifically, this research provides converging evidence that the specific effects that sensory experience has on early perceptual development are likely to depend on a number of interrelated factors, including (a) the timing of sensory experience, (b) the amount of sensory experience, and (c) the type of sensory experience encountered by the embryo or fetus.

For example, Sleigh and Lickliter (1996) showed that augmented amounts of prenatal auditory stimulation can result in either a developmental delay or acceleration of species-typical patterns of early intersensory development in bobwhite quail embryos and hatchlings, depending on the particular type of auditory stimulation to which the embryo is exposed. In this study, providing quail embryos with augmented amounts of their own prenatal contentment calls resulted in an acceleration of the onset of postnatal intersensory responsiveness to maternal auditory and visual information in the days following hatching, whereas providing embryos prenatal exposure to augmented amounts of their own distress vocalizations resulted in delayed postnatal emergence of intersensory responsiveness to maternal stimulation when compared with controls. The finding that altered stimulation to the earlier developing auditory modality can affect subsequent intraand intersensory responsiveness indicates a strong relationship of influence between the sensory modalities during the late prenatal period.

Related comparative research also suggests that some optimal level of overall sensory stimulation is required during perinatal development. This theme, that substantial increases or decreases in the range (amount and type) of stimulation normally present in the young organism's prenatal developmental milieu can result in altered arousal and attention levels and lead to subsequent deficits in intra- and intersensory functioning during the postnatal period, has received support from a number of recent studies (Banker $\&$ Lickliter, 1993; Carlsen \& Lickliter, 1999; Gottlieb, 1993; Lickliter \& Lewkowicz, 1995; Radell \& Gottlieb, 1992; Sleigh, Columbus, \& Lickliter, 1996; Sleigh \& Lickliter, 1995, 1997). As a case in point, bobwhite quail embryos reared in their typical developmental context in ovo (with no patterned visual stimulation present) were capable of learning an individual bobwhite maternal call prenatally. In contrast, quail embryos provided with an increase in the amount and type of sensory stimulation present (patterned visual stimulation following removal of the upper portion of the eggshell) did not learn an individual maternal call in the period prior to hatching (Lickliter \& Hellewell, 1992). In this particular example, the effectiveness of the embryo's prenatal exposure to an individual maternal call was dependent on other features of the developmental system, namely, the absence of exposure to concurrent visual experience. Gottlieb, Tomlinson, and Radell (1989) provided parallel results in ducklings. These findings are consistent with those from human infants regarding the importance of overall amount of stimulation to patterns of arousal and attention in the weeks following birth (see, e.g., Gardner \& Karmel, 1995; Lewkowciz \& Turkewitz, 1980, 1981) and suggest the need for further research on the range of sensory stimulation optimal for supporting normal patterns of early perceptual and cognitive functioning in both full-term and preterm infants.

For example, the comparative findings regarding the role of both type and amount of sensory stimulation highlight the contextsensitive nature of early perceptual development and raise questions regarding the design of care environments for preterm human infants (see Lawson, Daum, \& Turkewitz, 1977; Philbin, Ballweg, \& Gray, 1994). The preterm infant typically receives decreased amounts of some patterns of sensory stimulation normally present in the intrauterine environment (vestibular stimulation from maternal movements) and increased amounts of other types of stimulation not normally present until later stages of development (unfiltered auditory stimulation and patterned visual stimulation). Recent work with animal subjects has repeatedly shown that unusually early (prenatal) exposure to patterned light (and the resulting earlier onset of visual functioning) can alter the subsequent responsiveness of both the visual system and the earlier developing auditory and olfactory systems, which normally function prenatally in the absence of input to the visual system (Gottlieb, Tomlinson, \& Radell, 1989; Kenny \& Turkewitz, 1986; Lickliter, 1990, 1993; Sleigh \& Lickliter, 1995). Because of the successive onset of function among the various sensory modalities (tactile $\rightarrow$ vestibular $\rightarrow$ chemical $\rightarrow$ auditory $\rightarrow$ visual), each sensory system has a unique developmental history by the time of birth or hatching, and alterations of typical perinatal sensory stim- 
ulation histories may have significant effects on perceptual responsiveness. It is becoming increasingly clear that explanations of early intersensory capacity that overlook the prenatal period and use birth as a starting point for developmental analysis are likely to be incomplete and overly simplistic in their conclusions.

The link between typical patterns of perinatal stimulation and developmental outcome is gradually becoming assimilated into work with human neonates. For example, Schanberg and Field (1987) successfully applied research on the role of tactile stimulation on the growth of rat pups to low-birthweight premature human infants. They found that premature infants who were regularly given gentle stroking gained weight more rapidly and were released from the hospital sooner than control infants. In a similar vein, patterned vestibular stimulation has been show to reduce the frequency of apnea in premature human infants and to facilitate the development of a variety of motor and perceptual skills in preterm infants (Korner, 1985, 1990). Ongoing research in medicine, nursing, and occupational and physical therapy is also actively assessing the relationship between perinatal stimulation and developmental outcome, particularly in terms of the type, patterning, sequencing, and timing of stimulation provided (see Mueller, 1996, for a review).

It is important to note that the experiential factors that appear to contribute to the development of various physiological and psychological abilities during early development are not always obvious or straightforward and can require repeated probes at more than one level of analysis or with various animal species to be identified (Gottlieb, 1991a). For example, a developmental relationship between specific factors contributing to normal perceptual organization may be readily evident in one species but be present in another species in a more subtle (and easily missed or overlooked) manner. Work with human neonates has repeatedly shown that stimulus characteristics such as intensity or amount of stimulation can interact with organismic characteristics such as the state of arousal of the infant and the larger context of the infant to contribute to the infant's emerging perceptual skills and capacities (Lewkowitz \& Turkewitz, 1981; Turkewitz, Lewkowitz, \& Gardner, 1983). For neonates, arousal and attention can be characterized as a single, quantitatively organized, self-limiting homeostatic system that combines the effects of internal (state, arousal level) and external (stimulus intensity, immediate context) factors to systematically influence directional shifts in attention to particular stimuli (Gardner \& Karmel, 1995). This insight suggests a similar pattern of relationship might exist for other species, and recent work with precocial avian embryos and hatchlings and altricial rat pups has likewise found that the salience of particular patterns of sensory stimulation appear dependent on the total context of presentation (including both internal and external factors) and not simply on specific physical features or amount of stimulus energy (Arnold \& Spear, 1997; Lickliter \& Lewkowitz, 1995; Radell \& Gottlieb, 1992; Sleigh \& Lickliter, 1996, 1997; Spear \& McKinzie, 1994).

This theme, that control for specific developmental outcomes resides in the structure and nature of the relationships within and between internal and external variables (rather than in any individual factor), is still not widely appreciated in many developmental research designs but clearly has important implications for the study of early perceptual organization (Lickliter, 1995; Turkewitz, Lewkowicz, \& Gardner, 1983). These include an empirical appre- ciation that perceptual development is a process that is "situated" (i.e., takes place in a context) and a focus on experimentally specifying how external stimulative events can coact with organismic factors to exert particular effects on specific traits or characteristics at particular times. This approach is becoming increasingly apparent in the study of early brain-behavior relationships associated with perceptual development and organization, an area of investigation that has also relied heavily on animal-based research.

\section{Brain-Behavior Relationships Underlying Intersensory Perception}

The study of how information from the different senses is integrated in the brain is of growing interest not only to developmental psychologists but also to investigators working in developmental biology, psychobiology, and the neurosciences. These related disciplines offer a rich source of information regarding the development of intermodal perception. In particular, comparative neuroanatomical and neurophysiological studies with a variety of animal species are providing insight into how young infants determine which patterns of stimulation belong together and originate from a single object or event and which patterns of stimulation are unrelated (Knudsen \& Brainard, 1995; Wallace \& Stein, 1997).

Studies have repeatedly shown that newborn animals have wellorganized inputs from different sensory modalities converging on the same target structure in the brain (Frost, 1984; Innnocenti \& Clarke, 1984; Roe, Pallas, Hahm, \& Sur, 1990). This multisensory convergence can even be seen in brain structures that are known to be essentially unimodal at maturity. Such findings have led Stein and Meredith (1993) to argue that at an anamical level, the fetal and newborn brains of many animals are more multisensory than those of the same animals when they are adults. For example, Almli and Fisher (1984) found that the number of different sensory modalities capable of activating single cells in the hypothalamus of the infant rat is greater at postnatal Day 5 than at Day 15 . Evidence from a number of animal species indicates that the fetal and neonatal experience of the young organism appears in large part to determine which convergence patterns survive and how the different sensory inputs are weighted functionally over the course of individual ontogeny (Knudsen, 1988; Knudsen \& Brainard, 1991). For example, the mutual alignment of visual and auditory space maps in the brain have repeatedly been shown to be calibrated by experience (see Knudsen \& Brainard, 1995, for a review).

Indeed, a fundamental insight from comparative work in psychobiology and the neurosciences is that stimulation from the external environment and from self-generated activity and feedback from behavior can have profound effects on the pattern of connectivity in the developing nervous system (see Fields \& Nelson, 1991, for a review). These effects can be detected by changes in the functional properties of the nervous system but are also demonstrated by structural changes in dendritic branching, synapse formation, and axonal branching as a function of experiential influences (Greenough \& Black, 1992). In regard to early intersensory perception, work with both birds and mammals provides abundant examples of such activity-dependent neural and developmental processes. Much of this work has utilized the fact that each sensory modality has its own spatial representation 
(receptive field) and that the alignment of these different sensory maps in the brain shows remarkable responsiveness to the organism's activity and experience.

A study by King, Hutchings, Moore, and Blakemore (1988) serves to illustrate this phenomenon. These investigators occluded one ear or deviated one eye of young ferrets during early postnatal development. In both cases, a shift in the animal's auditory receptive fields was found as a result of the experimental sensory modification. This functional shift in the young ferret's auditory map ensured the successful alignment of the ferret's auditory and visual inputs in the superior colliculus, a midbrain structure involved in attention and orientation. This finding (for a similar example with owls, see Knudsen, 1983) illustrates how stimulation to one sensory system's receptive field or map can exert powerful developmental influences on the induction and maintenance of another modality's spatiotopic neural map. Presumably, under normally occurring conditions, such map alignment results from ongoing experience with auditory and visual stimuli that are concurrently produced by the same object or event and are thus linked in time and space. For example, research on the sensory maps in the superior colliculus of the guinea pig has found that visual experience is required for the normal elaboration of the collicular map of auditory space (Withington-Wray, Binns, \& Keating, 1990). Guinea pigs raised in darkness failed to develop an auditory map, suggesting that normal development of a map of auditory space requires the coincident activation of neural activity deriving from both auditory and visual input arising from common stimuli. The activity-based alignment of the different sensory maps in the brain and the responsiveness of these areas to sensory experience are likely a critical feature of multisensory integration (Stein \& Meredith, 1993). In particular, the spatial register among the receptive fields of multisensory neurons in a variety of brain structures seems to provide a neural substrate for enhancing responses to stimuli that are spatially and temporally related. Work from the neuroanatomical and neurophysiological levels of analysis provides strong support for this view of early perceptual organization (King \& Palmer, 1985; Stein, Meredith, \& Wallace, 1994).

For example, Stein and Meredith (1993) reported that the effectiveness of a visual stimulus in eliciting attention and orienting behaviors in cats is dramatically affected by the presence of an auditory stimulus. They reported that vigorous responses can be evoked in superior colliculus neurons with the presentation of cues to a single sensory modality but that the magnitude of response is greatly enhanced by combinations of stimuli from two or more modalities. Multimodal stimulus combinations produce significant increases over unimodal responses in an array of extracellular measures of neural activity, including response reliability, number of impulses evoked, peak impulse frequency, and duration of the discharge train. Stein and Meredith concluded that the neural consequences of pairing two stimuli from different modalities exceed what would be expected by adding the consequences of each cue considered separately. This "multiplicative" effect of multimodal stimulation has also been supported in work with cats at the behavioral level of analysis (Stein, Meredith, Huneycutt, \& McDade, 1989). The performance of cats trained to approach a low-intensity visual cue was significantly enhanced when a brief, low-intensity auditory stimulus was presented at the same location as the visual cue; in contrast, performance was significantly de- pressed when the auditory stimulus was spatially disparate with respect to the visual cue. The multiplicative nature of auditory and visual interactions and its dependence on the relative positions of the two stimuli were very similar to the pattern of relationship observed physiologically in single-cell preparations, suggesting that the rules governing multisensory integration at the level of the cell can also apply to behavioral responsiveness.

Behavioral research with precocial birds has also demonstrated that developmental processes involving both visual and auditory sensory experience appear to underlie the emergence of early intersensory responsiveness, further highlighting the activitydependent nature of perceptual development and the strong influence between the sensory modalities during early development. Quail chicks receiving only maternal visual or maternal auditory (unimodal) cues in the period following hatching failed to show species-typical perceptual responsiveness when compared with control chicks receiving multimodal maternal experience (Sleigh, Columbus, \& Lickliter, 1998). In particular, chicks provided with only unimodal (auditory or visual) maternal experience showed delayed patterns of visual responsiveness to maternal information and reduced sensitivity to spatial colocation of auditory and visual stimulation when compared with control chicks reared with multimodal maternal stimulation (Columbus, Sleigh, Lickliter, \& Lewkowicz, 1998). Together, these results suggest that the developing quail chick requires both auditory and visual experience in the period following hatching to demonstrate species-typical perceptual skills. Experimentally altering normal patterns of auditory or visual experience during the perinatal period appears to interfere with the normal emergence of intersensory responsiveness and has recently been shown to alter neuroanatomical structure. Carlsen (1999) examined the effects of differing amounts of unusually early visual stimulation in the period prior to hatching on dendritic morphology of neurons in the visual Wulst, a structure similar to the mammalian visual cortex. Quail embryos exposed to prenatal visual stimulation showed altered patterns of intersensory responsiveness to maternal cues and were also found to have significant changes in the number of spines and degree of branching of dendrites in the Wulst when compared with control chicks not receiving prenatal visual stimulation. Chicks receiving relatively small amounts $(10 \mathrm{~min} / \mathrm{hr})$ of prenatal visual stimulation in the days prior to hatching showed enhanced audiovisual responsiveness to maternal cues and had significantly fewer dendritic spines than controls following hatching, whereas chicks receiving relatively large amounts $(40 \mathrm{~min} / \mathrm{hr})$ of prenatal visual experience showed delayed intersensory responsiveness and had a significantly greater number of spines and more branching than controls. How similar alterations in prenatal auditory experience (i.e., intermodal stimulation) would affect neuronal structure in the visual Wulst remains to be explored, but existing behavioral evidence demonstrating the effects of prenatal auditory stimulation on subsequent visual responsiveness (Lickliter \& Stoumbos, 1991; Sleigh \& Lickliter, 1997) suggests that similar patterns of neuronal change in visual areas are plausible following augmented prenatal auditory stimulation.

On a related note, several investigators working with human infants have reported findings that support the view that multimodal stimulation has greater perceptual salience than unimodal stimulation early in development. In a series of related studies, Lewkowicz (1988a, 1988b, 1992, 1996a) has shown that regard- 
less of the specific nature of the information specifying multimodal stimulation (e.g., flashing checkerboards and pure tones, moving objects and punctate sounds, human faces and voices), human infants consistently exhibited the capacity to discriminate changes in stimulation when those changes occurred in both the auditory and visual modalities concurrently. In contrast, when changes in stimulative features were unimodal (e.g., a change in the temporal rate of one component or a change in the gender of the speaker), discrimination was not always observed. Bahrick (1988, 1992, 1994) likewise provides converging lines of evidence for the power of redundant (amodal) information in guiding and constraining early intersensory responsiveness. In these related studies, amodal information, that is, information that is redundant across two or more senses, was found to direct infants' early perceptual learning and buffer them against learning incongruent or arbitrary intersensory relations. More specifically, following training, infants were able to learn to pair an object and sound together when they were united by amodal relations (temporal synchrony and composition) but not when the amodal information was incongruent (Bahrick, 1988). Such behavioral evidence is congruent with neurophysiological findings from animal subjects indicating the salience of concurrent bimodal stimulation to neuronal responsiveness and orientational behavior (Stein \& Meredith, 1993).

Taken as a whole, work concerned with multimodal stimulation in both birds and mammals and from both neurofunctional and behavioral studies underscores the notion that overlapping or redundant sensory information can provide the young organism with the potential for enhanced response, in that reaction to the presence of one stimulus can be altered by the presence of another stimulus in a different modality. Further, early intersensory responsiveness appears to be affected by the stage, state, and experiential history of the organism, the nature and history of sensory stimulation provided or denied, and the larger physical, social, and temporal context in which development occurs. Thus, context, along with specific organismic and stimulus features, is increasingly recognized as an important behavioral determinant.

\section{Context and Experience Variables Contributing to Intersensory Perception}

Although the importance of experience, milieu, or context has been acknowledged in the behavioral sciences for many years (see, e.g., Brunswik, 1952; Lewin, 1946; Werner, 1957), a concerted effort to include contextual and experiential factors in analytic studies of development is relatively recent (Ford \& Lerner, 1992; Gottlieb, 1971, 1997; Michel \& Moore, 1995; Wozniak \& Fischer, 1993). Historically, the science of psychology has tended to reduce the contexts of organisms to stimuli, often making little attempt to catalogue or examine the complex places and events within which behavioral development takes place (Reed, 1996). However, in recent years, those taking a systems approach to development have repeatedly highlighted the need for the specification of how external events coact with internal organismic factors to exert particular effects on specific traits or characters at particular times (Fischer \& Bidell, 1998; Ford \& Lerner, 1992; Gottlieb, 1991a; Lickliter, in press; Oyama, 1985; Thelen \& Smith, 1994; Turkewitz \& Devenny, 1993). As recently articulated by Fischer and Bidell (1998), development takes place in medias res, in the middle of things, not simply in the organism alone or in its brain. From this view, an organism's functional environment is structured, organized, and specific to the organism, and the task of defining the relevant physical, social, and temporal features of an organism's developmental context is an empirical problem requiring systematic description and analysis.

The recognition of a need for an empirical concern with the relationship between the organism and its environment has, of course, been evident in the work of several prominent students of perception over the past decades (see, e.g., Brunswik, 1952, 1956; E. J. Gibson, 1969). These authors have argued that, to construct psychological theories at an adequate level of complexity, it is necessary to study representative samples of both subjects and their situations. In other words, the relation between the organism and its environment, rather than simply the organism itself, is viewed as the appropriate object of study for psychology. J. J. Gibson $(1966,1979)$ is increasingly recognized for his ecological approach to the study of perception, in which the researcher is explicitly concerned with the structure of the environment, how the organism moves about in it, and what sorts of perceptual information the environment provides the perceiving organism. From J. J. Gibson's ecological approach, perception depends on the kinds of experiences that come from having a body with various sensory and motor capacities that are themselves embedded in a more encompassing physical, biological, and social context. Developmentalists concerned with intersensory perception are thus faced with the challenge of determining both how the immediate environment of the fetus or infant contributes to and constrains the perceptual information available to the young organism and how these contributions and constraints are themselves specified by the changing structure and capacities of the developing organism.

There has been relatively little empirical focus on this theme of the multidetermined nature of early perceptual development, but several investigators of human development have recently begun to implement such an approach (Adolph, Eppler, \& Gibson, 1993; Reed, 1996; Thelen et al., 1993). As a case in point, little is currently known about the perceptual consequences associated with the shift from relatively passive exploration of the surround (by prelocomotor infants in the months following birth) to more active exploration of the immediate environment (by crawling and walking infants during the later months of the first year; but see Bertenthal \& Campos, 1984; Eppler, 1995; Gustafson, 1984). Interestingly, Bertenthal and Campos (1990) found that perceptual responsiveness to objects and surfaces can change significantly following some experience with crawling. As new actions become available to the maturing infant, new opportunities for exploring the environment also emerge. Research with both avian and mammalian species has provided some insight into the formidable task of discovering and defining the various conditions, experiences, and events (both internal and external to the organism) that might be involved in this recursive aspect of early perceptual development.

Certainly, one of the most intriguing examples of this process is provided by the comparative work of Hein and his colleagues (Hein, 1980; Hein \& Diamond, 1983; Held \& Hein, 1963) concerned with the role of proprioceptive and tactile experience in the development of visual spatial representation in young kittens. Related studies demonstrated that visual stimulation provided by kittens' own locomotion was necessary for the normal develop- 
ment of eye-paw coordination and visually guided behavior. For example, eye-paw coordination developed normally in kittens that were allowed to simultaneously walk and look at objects or events but did not develop normally when kittens could only look at things while being moved passively (Held \& Hein, 1963). Similarly, kittens for whom there was no congruent relationship between visual input and their own body movements did not develop normal patterns of visually guided behavior. Visual feedback from movements of the kitten's paw was found to be essential to the emerging ability to guide the forelimb to visual targets; kittens denied visual feedback from locomotion consistently failed to develop visually guided reaching (Hein, 1980; for a similar example with monkeys, see Held \& Bauer, 1967). Of course, under normal developmental conditions, congruence between multimodal visual and proprioceptive stimulation is a regular aspect of kittens' postnatal experience, and such congruence appears to be an experiential requirement of normal perceptual organization. The availability of such multiple and redundant sources of information for modulating actions in response to local conditions is likely critical to the rapid development of postural control, reaching, sitting, and crawling seen over the course of infancy (Bertenthal, 1996).

Working at the physical and social levels of analysis, a number of studies utilizing precocial birds have also demonstrated that social interaction with conspecifics can facilitate the often rapid perceptual reorganization required during early development (see Lickliter, Dyer, \& McBride, 1993, for a review). In addition to providing nurturance and protection to the developing organism, the social environment provides a rich source of perceptual experience, including thermal, tactile, olfactory, auditory, and visual stimulation. This array of sensory stimulation arising from early social interaction can be critical to the emergence of normal patterns of intersensory development, and particular types and amounts of socially derived sensory stimulation have been found to dramatically influence animal infants' intra- and intersensory functioning during prenatal development (Gottlieb, 1980; Lickliter \& Lewkowitz, 1995; Sleigh \& Lickliter, 1997) and early postnatal periods (Columbus \& Lickliter, 1998; Gottlieb, 1991b, 1993; Lickliter \& Gottlieb, 1985; McBride \& Lickliter, 1993). These influences of early social interaction are often nonobvious, in that observed behaviors in response to one type of interaction (e.g., maternal stimulation) are often shaped and supported by early experiences with different types of interaction (e.g., sibling stimulation). For example, Lickliter and Lewkowitz (1995) showed the importance of prenatal tactile and vestibular stimulation provided by broodmates to the successful emergence of species-typical intersensory responsiveness to maternal cues in bobwhite quail chicks. In this study, quail embryos incubated in physical isolation during the late stages of prenatal development failed to show typical patterns of responsiveness to both maternal auditory and visual stimulation seen in communally incubated embryos. In addition, those embryos denied normal levels of tactile and vestibular stimulation from broodmates failed to demonstrate prenatal auditory learning of an individual maternal call, a behavior reliably seen in unmanipulated, communally incubated embryos. Columbus and Lickliter (1998) recently found similar results during the postnatal period, in that chicks reared with altered tactile, auditory, or visual experience with siblings showed delayed responsiveness to species-specific maternal auditory and visual information when compared with control chicks receiving unmanipulated social interaction following hatching.

These results and those from related work concerned with social influences on sensitivity to spatial properties of stimulation (Lickliter, Lewkowicz, \& Columbus, 1996) underscore the fact that conspecifics are a rich experiential source of multimodal stimulation to the developing individual and can play a significant (but often nonobvious) role in the development of intersensory responsiveness. The infant's sensitivity to its social context and the contribution of social processes in perceptual development has been relatively overlooked in most laboratory studies of human infant perception (but see Stern, 1985; Walker-Andrews, 1997; Zukow-Goldring, 1997), suggesting that a greater research emphasis on the social factors of early perceptual development could pay significant dividends in defining the developmentally relevant components of both sensory and non-sensory factors contributing to early intersensory functioning.

\section{Current Examples of Convergent Operations in the Study of Intersensory Perception}

The material reviewed above highlights several related themes or principles regarding the development of intersensory perception. These themes of early perceptual development are woven throughout comparative research concerned with intersensory functioning and range from the important role of prenatal factors in subsequent postnatal perceptual organization to the activity- and context-dependent nature of infants' emerging intersensory abilities. Individual intersensory functioning is clearly multidetermined, with diverse internal and external variables interacting probabilistically in ways still poorly understood. In this light, a convergent-operations approach provides students of perceptual development with a useful framework that both acknowledges the complex and dynamic nature of development and attempts to integrate data from neuroscience, developmental biology, psychobiology, and developmental psychology into a coherent and complementary account of how young organisms achieve the unitary perception of objects and events. We believe an important step in this type of advance is increasing interaction and, when possible, collaboration between developmentalists working with animals and those studying humans. A working link between comparative and human research can allow a better empirical focus on the specific developmental processes underlying early intersensory perception. To illustrate the value of this approach, in this section, we briefly review several research areas in which such links are being forged to address current topics of interest.

\section{Effects of Unimodal Versus Bimodal Stimulation During Early Development}

The environment of infants is inherently multimodal in nature, with objects and events typically experienced through several sensory systems simultaneously. Developmental psychologists have often undercharacterized the importance of multimodal stimulation in their assessment of infants' developing skills and abilities. Studies of infants' perception, learning, memory, and language development often reduce bimodal input to noise and attempt to experimentally control or even omit such stimulation from their experimental designs. However, the development of 
learning, memory, and language skills is always situated in the context of a multimodal environment. There is an obvious concern that the developmental processes and mechanisms inferred from studies of infant responsiveness to unimodal stimulation may not generalize to the behavior of infants as it occurs in the multimodal context of the everyday world (Lewkowicz, 1996a). Studying the single sensory system can in many cases represent a deprivation or distortion of normally occurring patterns of sensory experience. More studies are needed with both human and animal infants that directly examine the effects of multimodal stimulation and the relationship between multimodal and unimodal stimulation in the development of perception, learning, memory, and other varied abilities.

For example, studies of "motherese," or infant-directed speech, in which adults adjust their speech patterns when communicating to infants, have identified several aspects of caretaker behavior that appear to highlight important speech information and to help infants begin to segment the speech stream (Cooper \& Aslin, 1989; Fernald, 1984; Werker \& McLeod, 1989). Infant-directed speech is inherently multimodal, and includes gesture, changing facial expression, and touch in addition to auditory information (Lewkowicz, 1996a; Walker-Andrews, 1997; Zukow-Goldring, 1997). Research is needed to better understand the role of this multimodal infant-directed communication in facilitating attention and its relation to early speech perception and production (Massaro, 1998; Werker \& McLeod, 1989). As reviewed earlier, recent evidence (Gogate \& Bahrick, 1998) suggests the importance of bimodal redundancy for the initial detection of vowel-object relations in infants. Seven-month-old infants detected the arbitrary intermodal relations between vocalizations and moving objects that were temporally synchonous after only 2-3 min of exposure. These arbitrary relations were, however, successfully detected by infants only when the object was shown moving in synchrony with the speech sounds, not when it was still or when it was moving out of synchrony with the speech sounds.

Findings from the comparative neurophysiological literature also highlight the differences in responsiveness to information presented redundantly across two sense modalities versus the same information presented in only one modality (Stein \& Meredith, 1993; Stein, Meredith, \& Wallace, 1994). As discussed in the section Brain-Behavior Relationships Underlying Intersensory Perception, there appears to be a multiplicative effect, where information presented in two modalities elicits more potent neural and behavioral responses than the same information presented unimodally. For example, the effectiveness of a visual stimulus in eliciting attentive and orienting behaviors in cats can be dramatically affected by the presence of a stimulus in the auditory modality. This pattern is also observed at the neuronal level, where weak responses evoked in superior colliculus neurons by the presentation of a single cue can be greatly enhanced by the bimodal presentation of sensory stimuli (Meredith, Nemitz, \& Stein, 1987; Meredith \& Stein, 1986). Bimodal stimuli produce significant increases in response over that observed to unimodal stimuli in a variety of extracellular measures of neural activity and indicate that, given the appropriate temporal and spatial coincidence, pairing two stimuli from different modalities can often elicit a response that is greater than the sum of its unimodal parts.

\section{The Role of Intersensory Redundancy in Guiding Attentional Selectivity and Perceptual Learning}

In light of the varied results concerning the functional distinction between unimodal and multimodal stimulation, we recently developed an "intersensory redundancy" hypothesis (Bahrick \& Lickliter, in press) that attempts to synthesize the knowledge gained from both research on animal and human intersensory development and findings from the neural level of analysis to identify some of the processes underlying the how of intersensory perception. Intersensory redundancy refers to the spatially coordinated and concurrent presentation of the same information (i.e., rate, rhythm, intensity) across two or more sensory modalities. For the auditory and visual modalities, this also entails the temporally synchronous alignment of the bimodal information. In brief, the intersensory redundancy hypothesis proposes that information presented redundantly across two or more sensory modalities selectively recruits infant attention during early development, causing amodal (redundant) stimulus properties to become foreground and other modality specific stimulus properties to become background. This selective attention on the part of the infant gives initial advantage to the perceptual processing, learning, and memory of stimulus properties that are bimodal over the processing, learning, or memory of unimodal properties of sensory stimulation. In other words, information that is simultaneously presented across two or more modalities is thought to be highly salient to infants and can direct attentional selectivity at the expense of information that is not redundant (see Bahrick \& Pickens, 1994; Bahrick, Walker, \& Neisser, 1981).

For example, in the Bahrick, Walker, and Neisser (1981) study, infants viewed films of two superimposed events (e.g., a moving toy slinky and a hand-clapping game). For the adult viewer, when the two superimposed events were viewed silently, they appeared to be an amalgamation of ghostly images passing through one another. However, as soon as the soundtrack to one was turned on, the sound-specified event suddenly stood out from the other event, creating a strong impression of figure and ground. Infants also appeared to be affected this way by the addition of the soundtrack. By playing the synchronous soundtrack to one of the superimposed events, the researchers were able to direct infants' attentional selectivity to that event, causing them to ignore the silent one. However, once the soundtrack was turned off and the films were separated (appearing side by side), intersensory redundancy was no longer available, and infants preferred to view the novel, previously silent film. Control studies confirmed this interpretation, in that when infants were presented with only one centrally projected event with sound, followed by silent trials of the two events side by side (familiar vs. novel films), they preferred the not previously visible (novel) film. Together these results demonstrate that the intersensory redundancy provided by the natural, synchronous soundtrack to a visible event can guide infants' visual selectivity, even when another visual event occupies the same spatial location.

Several aspects of the intersensory redundancy hypothesis have recently been supported, including the relative power of redundancy to guide attentional selectivity and perceptual learning in early infancy (Bahrick \& Lickliter, in press). In this study, 5-month-old infants were habituated to films of a hammer tapping out one of two distinct irregular rhythms. The rhythms were 
presented visually or acoustically (unimodal condition) or visually and acoustically (bimodal condition). Infants then received test trials depicting either a change in rhythm or no change in rhythm. Results indicated that infants were able to discriminate between the two irregular rhythms when they were presented bimodally (across both the auditory and visual modalities) but not when the rhythms were presented unimodally (only in the auditory or visual modality) or out of temporal synchrony. Concurrent and redundant stimulation to the auditory and visual modalities appeared to selectively guide infants' attention to the bimodally specified property of rhythm, fostering successful discrimination, whereas unimodal stimulation did not. It is important to note that the importance of redundant stimulation for directing attentional selectivity is expected to be most pronounced during early perceptual learning in a given domain, as infants are clearly capable of detecting amodal stimulus properties in unimodal stimulation within the first months of life (Rose \& Ruff, 1987).

Aspects of the intersensory redundancy hypothesis have also been explored in work with precocial animal infants. The findings from this research have also emphasized the functional distinction between unimodal and multimodal stimulation during early development. Specifically, studies of precocial bird embryos and hatchlings have consistently demonstrated that subjects denied normal levels of multimodal stimulation during the early postnatal period show impaired perceptual responsiveness to both multimodal and unimodal stimulation. For example, quail chicks receiving exposure to unimodal (either auditory or visual) maternal stimulation following hatching showed altered responsiveness to both unimodal and bimodal maternal cues. Regardless of whether their unimodal maternal experience was auditory or visual, chicks demonstrated enhanced auditory and delayed bimodal responsiveness when compared with control chicks receiving typical levels of multimodal stimulation (Sleigh, Columbus, \& Lickliter, 1998). Related work with both quail chicks and ducklings on the effects of the reduction of multimodal stimulation following hatching has also demonstrated altered patterns of auditory learning (Gottlieb, 1993; Lickliter \& Hellewell, 1992) and intersensory functioning (Columbus \& Lickliter, 1998). These results further support the functional distinction between unimodal and bimodal stimulation early in development and highlight the importance of bimodal stimulation to the normal emergence of intra- and intersensory functioning (see Knudsen \& Brainard, 1991, 1995, for similar examples drawn from the neuroanatomical level of analysis). More research with both animal and human subjects is needed to further examine and clarify the role of intersensory redundancy during prenatal and postnatal periods of development on perception, learning, and memory.

\section{Temporal and Spatial Features of Sensory Stimulation}

Animal and human research programs have tended to emphasize and experimentally manipulate different aspects of early intersensory perception. For example, research on human intersensory perception has typically investigated the effects of temporal parameters (e.g., synchrony, tempo, thythm) on the development of intersensory abilities (see Lewkowicz \& Lickliter, 1994a; Rose \& Ruff, 1987, for reviews). Surprisingly little research has been conducted on the role of spatial features of sensory stimulation in the development of human infants' intersensory perception (see
Field, 1987; Morrongiello, 1994, for reviews). In contrast, research with animal subjects has emphasized the role of spatial parameters on the intersensory preferences of animal infants and has typically overlooked the role of temporal properties of bimodal stimulation (see, e.g., Knudsen \& Knudsen, 1989, 1990; Lickliter, Lewkowicz, \& Columbus, 1996; Tees \& Symons, 1987).

The overwhelming focus on temporal properties (such as synchrony and rate of bimodal stimulation) in the human literature and on spatial properties of multimodal stimulation in the animal literature is likely due, at least in large part, to the inherent force of methodological tradition. For example, early studies of human infant intersensory perception used an intermodal preference procedure in which spatial cues were eliminated as a basis for matching visual and auditory stimulation (see, e.g., Spelke, 1976, 1979). In this procedure, sound emanates from a speaker positioned between two visual displays rather than being spatially colocated with either visual display. Widespread use of this method has fostered a research emphasis on the role of temporal properties in the development of intermodal perception, leaving the implicit impression that spatial properties are somehow less important in early perceptual development. On the other hand, the design of studies of animal infants' intersensory perception has tended to use the young organism's locomotor skills as a means of assessing the infant's ability to respond to multimodal stimulation (Kenny \& Turkewitz, 1986; Lickliter, Lewkowicz, \& Columbus, 1996; Symons \& Tees, 1990; Tees, 1994). Because most animal infants are able to walk soon after birth or hatching (and do not require restraint in an infant seat as do human subjects), comparative investigators have capitalized on movement and proximity-seeking behavior to investigate infants' sensitivity to the spatial colocation of bimodal stimulation. The availability of such measures as latency and duration of approach to various stimulus configurations, pecking or bar pressing behaviors, and other motor-based patterns of responsiveness has resulted in the undercharacterization of the role of temporal features of bimodal stimulation in much of the comparative literature.

It is clear, however, that spatial properties are important determinants of human infants' intersensory functioning (Fenwick \& Morrongiello, 1998; Lawson, 1980; Lyons-Ruth, 1977; Morrongiello, 1994), and temporal properties are likewise known to be important in guiding animal infants' intersensory functioning (Sleigh, Columbus, \& Lickliter, 1998; Spear \& Kucharski, 1984; Spear \& McKinzie, 1994). Given that all sensory stimulation occurs in space and time, neither property should be overlooked or undercharacterized in attempts to understand early intersensory functioning. This is an obvious area in which a better integration of the animal and human literatures should lead to more comprehensive understanding of intersensory perception. In particular, what is needed is a more explicit concern with the nature of the interaction between spatial and temporal information underlying early intersensory development (see Kubovy, 1988). Given that both spatial and temporal properties contribute to infants' intersensory perception, how do spatial features influence the detection and processing of temporal features of multimodal stimulation and vice versa? Does vision have a more powerful influence on the perception of spatial intermodal relations and audition a stronger influence on the perception of temporal intermodal relations? Does the nature of the relationship between spatial and temporal information change over the course of development? Little is currently 
known about these important questions, but forging a closer link between animal- and human-based research programs could allow complementary investigation of the influence and interaction of temporal and spatial factors in the development of intersensory abilities.

\section{Conceptual and Empirical Applications of a Convergent- Operations Approach: Status and Strategy}

As briefly reviewed above, research with human subjects and with animal subjects (which allows the manipulation and control of prenatal and postnatal environments) can combine, at least in some cases, to yield insight into and direction toward areas and topics of growing interest to students of intersensory perception. The synthesis of perspectives from multiple species and levels of analysis can provide a broader understanding of the processes of development by explicating specific conceptual and methodological tools for studying and explaining the dynamics of early intersensory functioning. Several examples of such conceptual and methodological insights applied to perinatal development include the following:

(1) Birth is not an adequate starting point for explanations of development. At birth, the human infant has already had a great deal of prenatal experience, and the nature and type of this experience must be taken into account when seeking explanations of the origins of human behavior (see, e.g., DeCasper \& Fifer, 1980; DeCasper \& Spence, 1986; Fifer \& Moon, 1989; Marlier, Schaal, \& Soussignan, 1998). The old view that the characteristics infants display at birth are attributable to genetics and those that develop postnatally are attributable to experience is clearly outdated and misguided. It is important to remember that all of the human infant's sensory modalities are capable of function in the prenatal period and that, with the exception of vision, all the senses are subject to ongoing stimulation during the prenatal period (Gottlieb, 1971). Consequently, human infants are not sensorally naive at birth, even though this fact is rarely acknowledged by investigators of infant perceptual development (but see Lecanuet, GranierDeferre, \& Busnel, 1995; Schaal, Marlier, \& Soussignan, 1998).

(2) The sensory modalities do not emerge simultaneously but become functional during prenatal development in an invariant sequence. In precocial animal and human infants, tactile and vestibular functioning precedes auditory functioning during prenatal development, and visual functioning does not emerge until birth (Gottlieb, 1971). This successive onset of the senses is not typically acknowledged by researchers conducting studies with humans, but such knowledge could facilitate several new directions in psychologists' thinking about intersensory development. First, since the modalities have different developmental histories, they are not on an equal footing at birth. Consequently, the infant's ability to abstract information may be more developed in some modalities than others. Some researchers have argued that some sensory modalities are "dominant" over other modalities at birth, specifically those with longer developmental histories (see Lewkowicz, 1988a, 1988b, 1994; Lickliter, 1994). Alternatively, it may be useful to consider that certain properties of objects and events (rather than sensory modalities per se) are more salient than other properties because of the organism's prenatal history. For example, temporal properties such as synchrony, tempo, and rhythm are available through vestibular, tactile, and auditory stim- ulation in utero. In contrast, spatial properties that are abstracted most readily through the visual modality (such as location or orientation) are not typically available prenatally. Thus, at birth, infants may have experience detecting some object/event properties (such as temporal properties) and not others (such as some spatial properties), creating initial "salience hierarchies" for object/ event properties. Such hierarchies and their potential implications for early perceptual organization have rarely been discussed or explored (but see Bushnell, 1994; Morrongiello, Fenwick, \& Chance, 1998; Turkewitz, 1994) and have not been explicitly linked to experience during prenatal development. More research designed to examine the contribution of spatial factors relative to temporal ones in the perception of intermodal unity is clearly needed.

(3) The successive emergence of the senses serves to regulate and constrain the nature and amount of sensory input during prenatal development. The gradual and sequential onset of function within the modalities allows for the development of initial functioning in each modality without competing stimulation from later developing modalities (Turkewitz \& Kenny, 1982). Recent comparative research has repeatedly shown that the timing of the onset of different types of sensory stimulation is important for normal perceptual development (Carlsen \& Lickliter, 1999; Gottlieb, Tomlinson, \& Radell, 1989; Lickliter, 1993; Sleigh \& Lickliter, 1998). This work suggests that normal developmental outcomes are as much the result of typical constraints and limits on the range and type of stimulation infants experience at different developmental phases as they are the result of the sensory experience infants actually do receive (see Oyama, 1993, for a further discussion of constraints in development). Prior to birth, the developing fetus resides in a relatively sequestered and simplified environment. Present knowledge suggests that the order and constraint provided by the sequential onset of sensory function prenatally and the simplified nature of the uterine environment combine to effectively regulate the amount, type, and timing of information available to the fetus. The emergence of visual functioning and the increasingly multimodal nature of sensory stimulation following birth signal a major shift forward in the nature of the young organism's capacity and experiential milieu. A core of basic behavioral and physiological data on the attentional, sensory, motor, and social factors associated with this shift is needed to better understand the developmental background of early intersensory functioning.

(4) The sensory modalities are linked during the perinatal period. Experimental manipulations that augment or attenuate sensory stimulation in one modality often lead to complex effects on the development of perception in other sensory modalities and on the development of intersensory functioning during the early postnatal period (Lickliter \& Banker, 1994; Radell \& Gottlieb, 1992; Sleigh \& Lickliter, 1997; Turkewitz, Gilbert, \& Birch, 1974). These results highlight the interconnectedness of the senses during early development and point to the importance of considering the existence of some forms of intersensory relationships during the prenatal period in the human infant. Functioning tactile, vestibular, chemical, and auditory modalities are interacting during later stages of prenatal development and likely influence patterns of subsequent postnatal intersensory functioning. Little is known about the nature of these interactions and their possible contributions to the newborn's perceptual preferences (Turkewitz, 1994). 
In addition to these conceptual and methodological insights regarding prenatal development, several others can be highlighted regarding the study of postnatal development.

(5) Better methods are needed for assessing both organismic and environmental factors contributing to the emergence of intermodal abilities. The majority of work on infant intersensory perception has focused on questions of what and when rather than how. As a result, little is known regarding the interplay of internal and external factors thought to be involved in the achievement of early intersensory integration. We have discussed how the roles of the infant's arousal, attention, and previous experience and of context and social interaction on intersensory functioning remain relatively unexplored at present. Work with special populations who have particular sensory impairments can be particularly informative in this task, as these infants have both altered sensory systems and altered environmental input over the course of early ontogeny. For example, research with the blind or deaf child can provide important suggestions about how the perceptual systems influence one another and how typical or normal patterns of intersensory functioning are achieved during development. In this light, Quittner, Smith, Osberger, Mitchell, and Katz (1994) examined the role of auditory experience in the development of visual attention by studying deaf children who either had or did not receive cochlear implants. Deaf children without implants performed much more poorly on a visual attention task than did their hearing (implanted) counterparts. A related longitudinal experiment showed that the rate of development in visual selective attention was faster for deaf children with cochlear implants than deaf children without implants, suggesting that the history of auditory experience can influence the development of visual attention.

(6) Researchers should increase their focus to how context or milieu both constrains and guides early development. The infant's effective environment becomes more extended and diverse with development as the infant progresses from lying to sitting to crawling and walking. The onset of independent locomotion greatly extends both the range and type of stimulation the infant encounters, allowing for different types of interactions with the environment (Bertenthal, 1996; E. J. Gibson, 1988; Rochat, 1992). The impact of these changes on the development of intersensory perception could be more explicitly investigated (see Eppler, 1995 , for an example). One obvious possibility is that the early prelocomotor period constrains infant attention to more proximal stimuli. In particular, it may focus infant attention on the infant's own body and on the face of the caretaker. Attention to the infant's body allows for a great deal of experience with intermodal stimulation originating from the self (see Rochat, 1995, for multiple examples). The concurrent manipulation of objects and visual regard of the hand and the active self-exploration seen in infancy certainly provide a rich source of systematic intersensory experience. When the infant moves his or her body, he or she receives simultaneous stimulation from proprioceptive/tactile feedback and from the visual and auditory consequences of self-motion. Young infants are known to be sensitive to these intermodal relations generated from self-motion (Bahrick \& Watson, 1985; Rochat \& Morgan, 1995; Schmuckler, 1996), and intersensory research would benefit from studies designed to examine how such sensitivities contribute to and change with early perceptual development. Similarly, the focus of infant attention on the face of the caregiver also provides a rich source of intersensory stimulation and may be linked to the emergence of communicative skills (Gogate \& Bahrick, 1998; Moore \& Dunham, 1995; Muir \& Hains, 1993). More detailed and systematic study of the aspects of caregiver-infant interaction that support this type of development and how it changes with the infant's developing locomotor and social skills is needed.

(7) The fact that perception is "embodied" could be more fully taken into account in the empirical designs of intersensory research. Perception cannot be meaningfully separated from the self that perceives. Comparative research has repeatedly highlighted the fact that different organisms experience the world differently because of the differences in the physical nature and size of their bodies, the ways in which they get around in the world, and the nature of their particular perceptual systems (Gibson, 1966; Khayutin, 1985; von Uexkull, 1957). These differences create different affordances for action for different organisms experiencing the same environment or for the same organism at different developmental stages. Intersensory research can benefit from a more directed focus on how the body of the developing organism and its particular capabilities for perceiving and acting in its normal environment can support or constrain the development of particular intersensory capabilities and exploratory behaviors (Rochat, 1992; Van der Meer \& Van der Weel, 1995). The importance of the body as the vehicle for perceiving and what it can and cannot afford the infant in the way of interaction with its environment could be given more emphasis in intersensory research. As a case in point, although there is strong evidence that infants and toddlers can coordinate input from the different sources (e.g., visual, vestibular, and proprioceptive) to produce information concerning their body position (see Schmuckler, 1995, for a review), few studies have directly examined visual-proprioceptive intermodal perception (but see Bahrick \& Watson, 1985; Rochat \& Morgan, 1995; Schmuckler, 1996).

(8) More studies are needed that directly investigate the learning process as it relates to intersensory development. Most studies of intermodal perception have focused on assessing the range and nature of the infant's existing capabilities. These descriptive efforts are valuable but reveal little about how a particular ability emerges in development. Needed are more studies that examine the process of perceptual learning by teaching infants a particular skill in the lab and observing under what conditions this learning takes place (see, e.g., Bahrick, 1988; Lewkowicz, 1992) and longitudinal studies designed to assess changes in intersensory skills over time as they occur in the infant's normal environment. As emphasized over a decade ago in a review of infant intersensory perception (Rose \& Ruff, 1987), there remains a need for more studies that investigate not only the conditions under which a particular perceptual ability is manifest but also the conditions under which it is not observed. This approach requires multiplestudy experiments that are designed to assess both the enhancing and the limiting conditions (both internal and external to the developing organism) contributing to the acquisition of specific skills or capacities. This approach is in keeping with Klüver's (1931) method of "equivalent and nonequivalent stimuli." In this method, a series of different conditions is presented to subjects to establish the range of stimuli to which they do or do not respond. In particular, an attempt is made to identify a set of stimuli that elicit the same response (equivalent set) as well as a set of stimuli that elicit a different response (nonequivalent set). A comparison 
of the various properties of the two sets of stimuli then enables the identification of the property (or properties) present and common to the stimuli in the equivalent set but absent in the nonequivalent set (for examples from the study of visual perception and intersensory functioning, see Pickens, 1994; Proffitt \& Bertenthal, 1990).

(9) Research on early perceptual development has provided increasing evidence for the concept of equifinality - the notion that there is not one but potentially multiple paths to the same developmental outcome. The notion of equifinality has received renewed attention in the developmental literature, both from basic and applied perspectives (Fischer \& Bidell, 1998; Ford \& Lemer, 1992; Gottlieb, Wahlsten, \& Lickliter, 1998; Lerner, 1998; Miller, 1997; Richters, 1997; Thelen \& Smith, 1994), and is well documented in the comparative literature concerned with early perceptual development (see, e.g., Banker \& Lickliter, 1993; Lickliter \& Hellewell, 1992; Lickliter \& Lewkowicz, 1995; Miller, Hicinbothom, \& Blaich, 1990). The fact that there are potentially multiple developmental pathways to normal or species-typical outcomes argues against deterministic views of perceptual development and suggests the need for a greater appreciation of the influence of the relationship within and between different levels within the developmental system on normal developmental patterns. As recently pointed out by Fischer and Bidell (1998), when development is conceived of and analyzed as a constructive web instead of a linear ladder, the possibility for multiple pathways to the same phenotypic outcome becomes more evident and detectable.

Taken together, these insights regarding prenatal and early postnatal periods suggest that the topic of intersensory development is primed to benefit from studies designed from multiple perspectives and levels of analysis, ranging from the neural to the social, from animal to human. However, such investigations are not, in and of themselves, enough. A multileveled, comparative approach to the study of early perceptual development also requires careful integration of empirical observations both within and across domains and levels of study. In this light, it is important to recognize that a convergent-operations approach to developmental issues faces strong challenges in terms of how to achieve such integration. Given that different animal species have different ecologies, different bodily structures, and different developmental timeframes and trajectories, drawing generalizations about development across species requires careful and systematic analyses of the similarities and differences observed in early perceptual functioning (Schneirla, 1966). We know from experience the difficulties involved in trying to compare and contrast the behavior of nonhuman animal and human infants and in using observations from one species to inform, refine, and constrain inferences based on observations of another species. In addition, successful application of a convergent-operations approach typically requires investigators to bridge across-institution boundaries and to overcome the fact that researchers in different subdisciplines often frame their research questions differently, use different language for discussing similar phenomena, have different types of controls and measures, and draw from different literatures, even when investigating similar topics. Difficulties not withstanding, we believe that a comparative, convergent-operations approach can foster a broader perspective to basic research issues than more traditional species-specific approaches and can help to identify themes or principles of per- ceptual development that are potentially generalizable across species and across populations.

In this article, we have reviewed comparative research concerned with early intersensory development and have been able to identify several related themes or principles drawn from recent research that provide potential insight and direction in the study of human development. These include: (a) Perceptual development is activity dependent; (b) perceptual development is context sensitive; (c) perceptual skills and abilities are multidetermined, emerging from the relationship between internal and external factors; (d) intersensory linkages and interactions are common during prenatal and early postnatal development; (e) embryos, fetuses, and newborns are particularly sensitive to the overall amount of available sensory stimulation; and ( $f$ ) infants have a long history of sensory experience prior to birth. These themes serve to remind researchers that developmentalists concerned with intersensory perception are faced with the difficult challenge of determining both how the immediate environment of the fetus or infant contributes to and constrains the perceptual information available to the young organism and how the developing organism uses this information as its perceptual and cognitive capabilities change over time. Such a dynamic, multidetermined view of intersensory perception is in keeping with recent advances in developmental theory (Ford \& Lerner, 1992; Gottlieb, 1991a, 1997; Lerner, 1998; Thelen \& Smith, 1994).

Perhaps the most important step towards a more comprehensive approach to the study of intersensory perception is the acknowledgment that an emphasis on any single domain, be it genes, physiology, neuroanatomy, physical maturation, or social interactions, is too narrow and limited to adequately address the complex and multidetermined nature of development. Intersensory perception is multidetermined, and limiting developmental observation and exploration to only one level or one species raises the risk of overlooking or undercharacterizing the richly textured, dynamic nature of the developmental process. As pointed out by a number of developmentalists, the facilitation and articulation of a multidimensional, process-oriented perspective requires building research programs that go beyond single-variable designs (Fischer \& Bidell, 1998; Richters, 1997; Valsiner, 1987, 1998). Discovering common pathways across domains, contexts, and levels of analysis is important to generating fundamental developmental principles and a deeper understanding of the how of development. Examination of both the similarities and the differences of outcome across a variety of species and exploration of the bases for these effects is a useful and promising step to this end.

\section{References}

Adolph, K. E., Eppler, M. A., \& Gibson, E. J. (1993). Development of perception of affordances. In C. Rovee-Collier \& L. P. Lipsett (Eds.), Advances in infancy research (Vol. 8, pp. 52-98). Norwood, NJ: Ablex. Alberts, J. R. (1984). Sensory-perceptual development in the Norway rat: A view towards comparative studies. In R. Kail \& N. S. Spear (Eds.), Comparative perspectives on memory development (pp. 65-101). Hillsdale, NJ: Erlbaum.

Allen, T. W., Walker, K., Symonds, L., \& Marcell, M. (1977). Intrasensory and intersensory perception of temporal sequences in infancy. Developmental Psychology, 13, 225-229.

Almli, C. R., \& Fisher, R. S. (1984). Postnatal development of sensory 
influences on lateral hypothalamic neurons of the rat. Developmental Brain Research, 12, 55-75.

Als, H. (1995). The preterm infant: A model for the study of fetal brain expectation. In J.-P. Lecanuet, W. P. Fifer, N. A. Krasnegor, \& W. P. Smotherman (Eds.), Fetal development: A psychobiological perspective (pp. 439-471). Hillsdale, NJ: Erlbaum.

Alter, W. A., Hartgraves, S. H., \& Wayner, M. J. (1991). A review of animal to human extrapolation: Issues and opportunities. Physiology and Behavior, 5, 1-184

Arnold, H. M., \& Spear, N. E. (1997). Infantile amnesia: Using animal models to understand forgetting. Advances in the Study of Behavior, 26, 251-284.

Aslin, R., \& Smith, L. B. (1988). Perceptual development. Annual Review of Psychology, 39, 435-473.

Bahrick, L. E. (1987). Infants' intermodal perception of two levels of temporal structure in natural events. Infant Behavior and Develop. ment, 10, 387-416.

Bahrick, L. E. (1988). Intermodal learning in infancy: Learning on the basis of two kinds of invariant relations in audible and visible events. Child Development, 59, 197-209.

Bahrick, L. E. (1992). Infants' perceptual differentiation of amodal and modality specific audio-visual relations. Journal of Experimental Child Psychology, 53, 180-199.

Bahrick, L. E. (1994). The development of infants' sensitivity to arbitrary intermodal relations. Ecological Psychology, 6, 111-123.

Bahrick, L. E. (in press). Increasing specificity in the development of intermodal perception. In D. Muir \& A. Slater (Eds.), Classic readings in developmental psychology. Oxford, England: Basil Blackwell.

Bahrick, L. E., \& Lickliter, R. (in press). Intersensory redundancy guides attentional selectivity and perceptual learning in infancy. Developmental Psychology.

Bahrick, L. E., Netto, D. S., \& Hernandez-Reif, M. (1998). Intermodal perception of adult and child faces and voices by infants. Child Development, 69, 1263-1275.

Bahrick, L. E., \& Pickens, J. (1994). Amodal relations: The basis for intermodal perception and learning in infancy. In D. J. Lewkowicz \& $R$. Lickliter (Eds.), The development of intersensory perception: Comparative perspectives (pp. 205-233). Hillsdale, NJ: Erlbaum.

Bahrick, L. E., Walker, A. S., \& Neisser, U. (1981). Selective looking by infants. Cognitive Psychology, 13, 377-390.

Bahrick, L. E., \& Watson, J. S. (1985). Detection of intermodal proprioceptive contingency as a potential basis of self-perception in infancy. Developmental Psychology, 21, 963-973.

Banker, H., \& Lickliter, R. (1993). Effects of early or delayed visual experience on perceptual development in bobwhite quail chicks. Developmental Psychobiology, 26, 155-170.

Bertenthal, B. I. (1996). Origins and early development of perception, action, and representation. Annual Review of Psychology, 47, 431-459.

Bertenthal, B. I., \& Campos, J. J. (1984). A reexamination of fear and its determinants on the visual cliff. Psychophysiology, 21, 413-417.

Bertenthal, B. I., \& Campos, J. J. (1990). A systems approach to the organizing effects of self-produced locomotion during infancy. Advances in Infancy Research, 6, 51-98.

Birch, H., \& Lefford, A. (1963). Intersensory development in children. Monographs of the Society for Research in Child Development, 28 .

Birch, H., \& Lefford, A. (1967). Visual differentiation, intersensory integration, and voluntary motor control. Monographs of the Society for Research in Child Development, 32.

Botuck, S., \& Turkewitz, G. (1990). Intersensory functioning: Auditoryvisual pattern equivalence in younger and older children. Developmental Psychology, 26, 115-120.

Bower, T. G. R. (1974). Development in infancy. San Francisco: Freeman. Bradley, R. M., \& Mistretta, C. M. (1975). Fetal sensory receptors. Physiological Reviews, 55, 352-382.
Brunswik, E. (1952). The conceptual framework of psychology. Chicago: University of Chicago Press.

Brunswik, E. (1956). Perception and the representative design of experiments in psychology. Berkeley, CA: University of California Press.

Bushnell, E. W. (1982). Visual-tactile knowledge in 8-, 91/2, and 11-month old infants. Infant Behavior and Development, 5, 65-75.

Bushnell, E. W. (1994). A dual-processing approach to cross-modal matching: Implications for development. In D. J. Lewkowicz \& R. Lickliter (Eds.), The development of intersensory perception: A comparative perspective (pp. 19-38). Hillsdale, NJ: Erlbaum.

Carlsen, R. M. (1999). Neural plasticity and the development of intersensory functioning in bobwhite quail. Unpublished doctoral dissertation, Virginia Polytechnic Institute and State University, Blacksburg.

Carlsen, R. M., \& Lickliter, R. (1999). Augmented prenatal tactile and vestibular stimulation alters postnatal auditory and visual responsiveness in bobwhite quail chicks. Developmental Psychobiology, 35, 215-225.

Clifton, R. K., Rochat, P., Robin, D. J., \& Bertheir, N. E. (1994). Multimodal perception in the control of infant reaching. Journal of Experimental Psychology: Human Perception and Performance, 20, 876-886.

Columbus, R. F., \& Lickliter, R. (1998). Modified sensory features of social stimulation alter the perceptual responsiveness of bobwhite quail chicks. Journal of Comparative Psychology, 112, 161-169.

Columbus, R. F., Sleigh, M. J., Lickliter, R., \& Lewkowicz, D. J. (1998). Unimodal maternal experience interferes with responsiveness to the spatial contiguity of multimodal maternal cues in bobwhite quail chicks. Infant Behavior and Development, 21, 397-409.

Cooper, R. P., \& Aslin, R. N. (1989). The language environment of the young infant: Implications for early perceptual development. Canadian Journal of Psychology, 43, 247-265.

DeCasper, A. J., \& Fifer, W. P. (1980, June 6). Of human bonding: Newborns prefer their mothers' voices. Science, 208, 1174-1176.

DeCasper, A. J., \& Spence, M. J. (1986). Prenatal maternal speech influences newborns' perception of speech sounds. Infant Behavior and Development, 9, 133-150.

Dodd, B. (1979). Lip reading in infants: Attention to speech presented inand out-of-synchrony. Cognitive Psychology, 11, 478-484.

Domjan, M., \& Purdy, J. E. (1995). Animal research in psychology. American Psychologist, 50, 496-503.

Eppler, M. A. (1995). Development of manipulatory skills and the deployment of attention. Infant Behavior and Development, 18, 391-405.

Ettlinger, G., \& Wilson, W. A. (1990). Cross-modal performance: Behavioral processes, phylogenetic considerations and neural mechanisms. Behavioural Brain Research, 40, 169-192.

Fenwick, K. D., \& Morrongiello, B. A. (1998). Spatial co-location and infants' learning of auditory-visual associations. Infant Behavior and Development, 21, 745-760.

Fernald, A. (1984). The perceptual and affective salience of mothers' speech to infants. In L. Feagans, C. Garvey, \& R. Golinkoff (Eds.), The origins and growth of communication (pp. 5-29). Norwood, NJ: Ablex.

Field, J. (1987). The development of auditory-visual localization in infancy. In B. E. McKenzie \& R. H. Day (Eds.), Perceptual development in early infancy (pp. 175-197). Hillsdale, NJ: Erlbaum.

Fields, R. D., \& Nelson, P. G. (1991). Activity-dependent development of the vertebrate nervous system. Annual Review of Neuroscience, 14, 133-214.

Fifer, W. P., \& Moon, C. (1989). Psychobiology of newborn auditory preferences. Seminars in Perinatology, 13, 430-433.

Fischer, K. W., \& Bidell, T. R. (1998). Dynamic development of psychological structures in action and thought. In R. Lemer (Ed.), Handbook of child psychology: Vol. 1. Theoretical models of human development ( $\mathrm{pp}$. 467-561). New York: Wiley.

Fleischer, S. F., \& Turkewitz, G. (1984). The use of animals for understanding the effects of malnutrition on human behavior: Models vs. a 
comparative approach. In J. R. Galler (Ed.), Nutrition and behavior (pp. 37-61). New York: Plenum.

Ford, D. H., \& Lerner, R. M. (1992). Developmental systems theory: An integrative approach. Newbury Park, CA: Sage.

Foreman, N., \& Altaha, M. (1991). The development of exploration and spontaneous alteration in hooded rat pups: Effects of unusually early eyelid opening. Developmental Psychobiology, 24, 521-537.

Freeman, W. J. (1991). The physiology of perception. Scientific American, $264,78-85$

Friedes, D. (1974). Human information processing and sensory modality: Cross-modal functions, information complexity, and deficit. Psychological Bulletin, 81, 242-310.

Frost, D. O. (1984). Axonal growth and target selection during development: Retinal projections to the ventrobasal complex and other "nonvisual" structures in neonatal Syrian hamsters. Journal of Comparative Neurology, 230, 576-592.

Gagnon, R. (1995). Developmental aspects of alterations in fetal behavioral states. In J.-P. Lecanuet, W. P. Fifer, N. A. Krasnegor, \& W. P. Smotherman (Eds.), Fetal development: A psychobiological perspective (pp. 129-148). Hillsdale, NJ: Erlbaum.

Gardner, J., \& Karmel, B. (1995). Development of arousal-modulated visual preferences in early infancy. Developmental Psychology, 31, 473-482.

Gibson, E. J. (1969). Principles of perceptual learning and development. Englewood Cliffs, NJ: Prentice Hall.

Gibson, E. J. (1988). Exploratory behavior in the development of perceiving, acting, and the acquiring of knowledge. Annual Review of Psychology, 39, 1-41.

Gibson, J. J. (1966). The senses considered as perceptual systems. Boston: Houghton Mifflin.

Gibson, J. J. (1979). The ecological approach to visual perception. Boston: Houghton Mifflin.

Gogate, L. J., \& Bahrick, L. E. (1998). Intersensory redundancy facilitates learning of arbitrary relations between vowel sounds and objects in seven-month-old infants. Journal of Experimental Child Psychology, 69, 133-149.

Gottlieb, G. (1971). Ontogenesis of sensory function in birds and mammals. In E. Tobach, L. Aronson, \& E. Shaw (Eds.), The biopsychology of development (pp. 67-128). New York: Academic Press.

Gottlieb, G. (1976). Conceptions of prenatal development: Behavioral embryology. Psychological Review, 83, 215-234.

Gottlieb, G. (1980). Development of species-identification in ducklings: VI. Specific embryonic experience required to maintain species-typical perception in Peking ducklings. Joumal of Comparative and Physiological Psychology, 94, 579-587.

Gottlieb, G. (1991a). Experiential canalization of behavioral development: Theory. Developmental Psychology, 27, 4-13.

Gottlieb, G. (1991b). Social induction of malleability in ducklings. Animal Behaviour, 41, 953-962.

Gottlieb, G. (1993). Social induction of malleability in ducklings: Sensory basis and psychological mechanism. Animal Behaviour, 45, 707-719.

Gottlieb, G. (1997). Synthesizing nature-nurture: Prenatal origins of instinctive behavior. Mahwah, NJ: Erlbaum.

Gottlieb, G., \& Simner, M. L. (1969). Auditory versus visual flicker in directing the approach response of domestic chicks. Journal of Comparative and Physiological Psychology, 67, 58-63.

Gottlieb, G., Tomlinson, W. T., \& Radell, P. L. (1989). Developmental intersensory interference: Premature visual experience suppresses auditory learning in ducklings. Infant Behavior and Development, 12, 1-12.

Gottlieb, G., Wahlsten, D., \& Lickliter, R. (1998). The significance of biology for human development: A developmental psychobiological systems view. In R. Lerner (Ed.), Handbook of child psychology: Vol. 1. Theoretical models of human development (pp. 233-273). New York: Wiley.
Greenough, W. T., \& Black, J. E. (1992). Induction of brain structure by experience: Substrates for cognitive development. In M. Gunnar \& C. A. Nelson (Eds.), Behavioral developmental neuroscience: Vol. 24. Minnesota Symposia on Child Psychology (pp. 155-200). Hillsdale, NJ: Erlbaum.

Gustafson, G. (1984). Effects of the ability to locomote on infants' social and exploratory behaviors: An experimental study. Developmental Psychology, 20, 397-405.

Haith, M. M. (1993). Preparing for the 21st century: Some goals and challenges for studies of infant sensory and perceptual development. Developmental Review, 13, 354-371.

Hein, A. (1980). The development of visually guided behavior. In C. S. Harris (Ed.), Visual coding and adaptability (pp. 51-67). Hillsdale, NJ: Erlbaum.

Hein, A., \& Diamond, R. M. (1983). Contribution of eye movement to the representation of space. In A. Hein \& M. Jeannerod (Eds.), Spatially oriented behavior (pp. 119-133). New York: Springer-Verlag.

Held, R., \& Bauer, J. A. (1967, October 20). Visually guided reaching in infant monkeys after restricted rearing. Science, 158, 390-392.

Held, R., \& Hein, A. (1963). Movement-produced stimulation in the development of visually guided behavior. Journal of Comparative and Physiological Psychology, 56, 872-876.

Hofer, M. A. (1987). Early social relationships: A psychobiologist's view. Child Development, 58, 633-647.

Innocenti, G. M., \& Clarke, S. (1984). Bilateral transitory projection to visual areas from auditory cortex in kittens. Developmental Brain Research, 14, 143-148.

James, D., Pillai, M., \& Smoleniec, J. (1995). Neurobehavioral development in the human fetus. In J.-P. Lecanuet, W. P. Fifer, N. A. Krasnegor, \& W. P. Smotherman (Eds.), Fetal development: A psychobiological perspective (pp. 101-128). Hillsdale, NJ: Erlbaum.

Johnston, T. D., \& Gottlieb, G. (1981). Development of visual species identification in ducklings: What is the role of imprinting? Animal Behaviour, 29, 1082-1099.

Kellman, P. J., \& Arterberry, M. E. (1998). The cradle of knowledge: Development of perception in infancy. Cambridge, MA: MIT Press.

Kenny, P., \& Turkewitz, G. (1986). Effects of unusually early visual stimulation on the development of homing behavior in the rat pup. Developmental Psychobiology, 19, 57-66.

Khayutin, S. N. (1985). Sensory factors in the behavioral ontogeny of altricial birds. Advances in the Study of Behavior, 15, 105-134.

King, A. J., Hutchings, M. E., Moore, D. R., \& Blakemore, C. (1988, March 3). Developmental plasticity in the visual and auditory representation in the mammalian superior colliculus. Nature, 332, 73-76.

King, A. J., \& Palmer, A. R. (1985). Integration of visual and auditory information in bimodal neurons in the guinea-pig superior colliculus. Experimental Brain Research, 60, 492-500.

Klüver, H. (1931). The equivalence of stimuli in the behavior of monkeys. Journal of Genetic Psychology, 39, 3-27.

Knudsen, E. I. (1983, November 25). Early auditory experience aligns the auditory map of space in the optic tectum of the barn owl. Science, 222 , 939-942.

Knudsen, E. I. (1988). Early blindness results in a degraded auditory map of space in the optic tectum of the barn owl. Proceedings of the National Academy of Sciences, 85, 6211-6214.

Knudsen, E. I., \& Brainard, M. S. (1991, July 5). Visual instruction of the neural map of auditory space in the developing optic tectum. Science, $253,85-87$.

Knudsen, E. I., \& Brainard, M. S. (1995). Creating a unified representation of visual and auditory space in the brain. Annual Review of Neuroscience, 18, 19-43.

Knudsen, E. I., \& Knudsen, P. F. (1989). Vision calibrates sound localization in developing barn owls. Journal of Neuroscience, 9, 33063313. 
Knudsen, E. I., \& Knudsen, P. F. (1990). Sensitive and critical periods for visual calibration of sound localization by barn owls. Journal of Neuroscience, 63, 131-149.

Korner, A. F. (1985). Preventative intervention with high-risk newborns: Theoretical, conceptual, and methodological perspectives. In J. D. Osofsky (Ed.), Handbook of infant development (pp. 1006-1036). New York: Wiley.

Korner, A. F. (1990). Infant stimulation: Issues of theory and research. Clinics in Perinatology, 17, 173-184.

Kubovy, M. (1988). Should we resist the seductiveness of the space:time:: vision:auditory analogy? Journal of Experimental Psychology: Human Perception and Performance, 14, 318-320.

Kuhl, P. K., \& Meltzoff, A. N. (1984). The intermodal representation of speech in infants. Infant Behavior and Development, 7, 361-381.

Kuo, Z.-Y. (1967). The dynamics of behavior development: An epigenetic view. New York: Random House.

Kuo, Z.-Y. (1970). The need for coordinated efforts in developmental studies. In L. R. Aronson, E. Tobach, D. S. Lehrman, \& J. S. Rosenblatt (Eds.), Development and evolution of behavior (pp. 181-193). San Francisco: Freeman.

Lawson, K. R. (1980). Spatial and temporal contruity and auditory-visual integration in infants. Developmental Psychology, 16, 185-192.

Lawson, K. R., Daum, C., \& Turkewitz, G. (1977). Environmental characteristics of a neonatal intensive care unit. Child Development, 48 , 1633-1639.

Lecanuet, J.-P., Fifer, W. P., Krasnegor, N. A., \& Smotherman, W. P. (Eds.). (1995). Fetal development: A psychobiological perspective. Hillsdale, NJ: Erlbaum.

Lecanuet, J.-P., Granier-Deferre, C., \& Busnel, M. C. (1995). Human fetal auditory perception. In J.-P. Lecanuet, W. P. Fifer, N. A. Krasnegor, \& W. P. Smotherman (Eds.), Fetal development: A psychobiological perspective (pp. 239-262). Hillsdale, NJ: Erlbaum.

Lerner, R. M. (1998). Theories of human development: Contemporary perspectives. In R. Lerner (Ed.), Handbook of child psychology: Vol. 1. Theoretical models of human development (pp. 1-24). New York: Wiley.

Lewin, K. (1946). Behavior and development as a function of the total situation. In L. Carmichael (Ed.), Manual of child psychology (pp. 791-844). New York: Wiley.

Lewkowicz, D. J. (1985). Developmental changes in infants' response to temporal frequency. Developmental Psychology, 21, 850-865.

Lewkowicz, D. J. (1986). Developmental changes in infants' bisensory response to synchronous duration. Infant Behavior and Development, 9, 335-353.

Lewkowicz, D. J. (1988a). Sensory dominance in infants: 1 . Six-month-old infants' response to auditory-visual compounds. Developmental Psychology, 24, 155-171.

Lewkowicz, D. J. (1988b). Sensory dominance in infants: 2. Ten-monthold infants' response to auditory-visual compounds. Developmental Psychology, 24, 172-182.

Lewkowicz, D. J. (1991). Development of intersensory functions in human infancy: Auditory/visual interactions. In M. J. Weiss \& P.R. Zelazo (Eds.), Newborn attention: Biological constraints and the influence of experience (pp. 308-338). Norwood, NJ: Ablex.

Lewkowicz, D. J. (1992). Responsiveness to auditory and visual components of a sounding/moving compound stimulus in human infants. Perception and Psychophysics, 52, 519-528.

Lewkowicz, D. J. (1994). Development of intersensory perception in human infants. In D. J. Lewkowicz \& R. Lickliter (Eds.), The development of intersensory perception: Comparative perspectives ( $\mathrm{pp} .165$ 203). Hillsdale, NJ: Erlbaum.

Lewkowicz, D. J. (1996a). Infants' response to the audible and visible properties of the human face: I. Role of lexical syntactic content, temporal synchrony, gender, and manner of speech. Developmental Psychology, 32, 347-366.

Lewkowicz, D. J. (1996b). Perception of auditory-visual temporal synchrony in human infants. Joumal of Experimental Psychology: Human Perception and Performance, 22, 1094-1106.

Lewkowicz, D. J., \& Lickliter, R. (Eds.). (1994a). The development of intersensory perception: Comparative perspectives. Hillsdale, NJ: Erlbaum.

Lewkowicz, D. J., \& Lickliter, R. (1994b). Insights into mechanisms of intersensory development: The value of a comparative, convergentoperations approach. In D. J. Lewkowicz \& R. Lickliter (Eds.), The development of intersensory perception: Comparative perspectives ( $\mathrm{pp}$. 403-413). Hillsdale, NJ: Eribaum.

Lewkowicz, D. J., \& Turkewitz, G. (1980). Cross-modal equivalence in early infancy: Auditory-visual intensity matching. Developmental Psychology, 16, 597-607.

Lewkowicz, D. J., \& Turkewitz, G. (1981). Intersensory interaction in newborns: Modification of visual preferences following exposure to sound. Child Development, 52, 827-832.

Lickliter, R. (1990). Premature visual stimulation accelerates intersensory functioning in bobwhite quail neonates. Developmental Psychobiology, $23,15-27$.

Lickliter, R. (1993). Timing and the development of perinatal perceptual organization. In G. Turkewitz \& D. A. Devenny (Eds.), Developmental time and timing (pp. 105-123). Hillsdale, NJ: Erlbaum.

Lickliter, R. (1994). Prenatal visual experience alters postnatal sensory dominance hierarchy in bobwhite quail chicks. Infant Behavior and Development, 17, 185-193.

Lickliter, R. (1995). Embryonic sensory experience and intersensory development in precocial birds. In J.-P. Lecanuet, W. P. Fifer, N. A. Krasnegor, \& W. P. Smotherman (Eds.), Fetal development: A psychobiological perspective (pp. 281-294). Hillsdale, NJ: Erlbaum.

Lickliter, R. (in press). Developmental systems and psychological science. In B. D. Midgley \& E. K. Morris (Eds.), Modern perspectives on J. R. Kantor and interbehaviorism. Hartford, CT: Greenwood Press.

Lickliter, R., \& Banker, H. (1994). Prenatal components of intersensory development in precocial birds. In D. J. Lewkowicz \& R. Lickliter (Eds.), The development of intersensory perception: Comparative perspectives (pp. 59-80). Hillsdale, NJ: Erlbaum.

Lickliter, R., Dyer, A. B., \& McBride, T. (1993). Perceptual consequences of early social experience in precocial birds. Behavioural Processes, 30 , 185-200.

Lickliter, R., \& Gottlieb, G. (1985). Social interaction with siblings is necessary for the visual imprinting of species-specific maternal preference in ducklings. Journal of Comparative Psychology, 99, 371-378.

Lickliter, R., \& Hellewell, T. B. (1992). Contextual determinants of auditory learning in bobwhite quail embryos and hatchlings. Developmental Psychobiology, 25, 17-24.

Lickliter, R., \& Lewkowicz, D. J. (1995). Intersensory experience and early perceptual development: Attenuated prenatal sensory stimulation affects postnatal auditory and visual responsiveness in bobwhite quail chicks. Developmental Psychology, 31, 609-618.

Lickliter, R., Lewkowicz, D. J., \& Columbus, R. F. (1996). Intersensory experience and early perceptual development: The role of spatial contiguity in bobwhite quail chicks' responsiveness to multimodal maternal cues. Developmental Psychobiology, 29, 403-416.

Lickliter, R., \& Stoumbos, J. (1991). Enhanced prenatal auditory experience facilitates postnatal visual responsiveness in bobwhite quail chicks. Journal of Comparative Psychology, 105, 89-94.

Lickliter, R., \& Virkar, P. (1989). Intersensory functioning in bobwhite quail chicks: Early sensory dominance. Developmental Psychobiology, 22, 651-667.

Lyons-Ruth, K. (1977). Bimodal perception in infancy: Response to auditory-visual incongruity. Child Development, 48, 820-827. 
Marks, L. E. (1978). The unity of the senses: Interrelations among the modalities. New York: Academic Press.

Marlier, L., Schaal, B., \& Soussignan, R. (1997). Orientation responses to biological odours in the human newborn: Initial pattern and postnatal plasticity. Neurosciences, 320, 999-1005.

Marlier, L., Schaal, B., \& Soussignan, R. (1998). Neonatal responsiveness to the odor of amniotic and lacteal fluids: A test of perinatal chemosensory continuity. Child Development, 69, 611-623.

Marshall-Baker, A., Lickliter, R., \& Cooper, R. P. (1998). Long-term exposure to a visual stimulus may promote behavioral organization in preterm infants. Journal of Perinatal and Neonatal Nursing, 12, 50-62.

Massaro, D. W. (1998). Perceiving talking faces: From speech perception to a behavioral principle. Cambridge, MA: MIT Press.

Maurer, D. (1993). Neonatal synesthesia: Implications for the processing of speech and faces. In B. de Boysson-Bardies, S. de Schonen, P. Jusczyk, P. McNeilage, \& J. Morton (Eds.), Developmental neurocognition: Speech and face processing in the first year of life (pp. 109-124). Boston: Kluwer Academic.

McBride, T., \& Lickliter, R. (1993). Social experience with siblings foster species-specific responsiveness to maternal cues in bobwhite quail chicks. Journal of Comparative Psychology, 107, 320-327.

McKenzie, B. G., \& Day, R. H. (Eds.). (1987). Perceptual development in early infancy. Hillsdale, NJ: Erlbaum.

Mellon, R. C., Kraemer, P. J., \& Spear, N. E. (1991). Intersensory development and Pavlovian conditioning: Stimulus selection and encoding of lights and tones in the preweanling rat. Journal of Experimental Psychology: Animal Behavior Processes, 17, 448-464.

Meltzoff, A. N. (1990). Towards a developmental cognitive science: The implications of cross-modal matching and imitation for the development of representation and memory in infancy. Annals of the New York Academy of Sciences, 608, 1-37.

Meltzoff, A. N., \& Borton, R. N. (1979, November 22). Intermodal matching by human neonates. Nature, 282, 403-404.

Mendelson, M. J., \& Ferland, M. B. (1982). Auditory-visual transfer in four-month-old infants. Child Development, 53, 1022-1027.

Meredith, M. A., Nemitz, J. W., \& Stein, B. E. (1987). Determinants of multisensory integration in superior colliculus neurons: I. Temporal factors. Journal of Neuroscience, 10, 3215-3229.

Meredith, M. A., \& Stein, B. E. (1986). Spatial factors determine the activity of multisensory neurons in the cat superior colliculus. Brain Research, 365, 350-354.

Michel, G. F., \& Moore, C. L. (1995), Developmental psychobiology: An interdisciplinary science. Cambridge, MA: MIT Press.

Miller, D. B. (1997). The effects of nonobvious forms of experience on the development of instinctive behavior. In C. Dent-Reed \& P. ZukowGoldring (Eds.), Evolving explanations of development (pp. 457-507). Washington, DC: American Psychological Association.

Miller, D. B., Hicinbothom, G., \& Blaich, C. F. (1990). Alarm call responsivity of mallard ducklings: Multiple pathways in behavioural development. Animal Behaviour, 39, 1207-1212.

Moore, C., \& Dunham, P. J. (1995). Joint attention: Its origins and role in development. Hillsdale, NJ: Erlbaum.

Morrongiello, B. A. (1994). Effects of colocation on auditory-visual interactions and cross-modal perception in infants. In D. J. Lewkowicz \& R. Lickliter (Eds.), The development of intersensory perception: Comparative perspectives (pp. 235-263). Hillsdale, NJ: Erlbaum.

Morrongiello, B. A., Fenwick, K. D., \& Chance, G. (1998). Cross-modal learning in newborn infants: Inferences about properties of auditoryvisual events. Infant Behavior and Development, 21, 543-554.

Mueller, C. R. (1996). Multidisciplinary research of multimodal stimulation of premature infants: An integrated review of the literature. Maternal-Child Nursing Journal, 24, 18-31.

Muir, D. W., \& Hains, S. M. J. (1993). Infant sensitivity to perturbations in adult facial, vocal, tactile, and contingent stimulation during face-to- face interactions. In B. de Boysson-Bardies, S. de Schonen, P. Jusczyk, P. McNeilage, \& J. Morton (Eds.), Developmental neurocognition: Speech and face processing in the first year of life (pp. 171-185). Dordrecht, The Netherlands: Kluwer.

Nijhuis, J. G., Martin, C. B., \& Prechtl, H. F. R. (1984). Behavioural states of the human fetus. In H. F. R. Prechtl (Ed.), Continuity of neural functions from prenatal to postnatal life. Oxford, England: Basil Blackwell.

Overmier, J. P., \& Burke, P. D. (1992). Animal models of human pathology: A bibliography of a quarter century of behavioral research, 19671992. Washington, DC: American Psychological Association.

Oyama, S. (1985). The ontogeny of information: Developmental systems and evolution. New York: Cambridge University Press.

Oyama, S. (1993). Constraints and development. Netherlands Journal of Zoology, 43, 6-16.

Piaget, J. (1952). The origins of intelligence. New York: Norton.

Philbin, M. K., Ballweg, D. D., \& Gray, L. (1994). The effect of an intensive care unit sound environment on the development of habituation in healthy avian neonates. Developmental Psychobiology, 27, 11-21.

Pickens, J. (1994). Perception of bimodal distance relations by 5-month-old infants. Developmental Psychology, 30, 537-544.

Proffitt, D. R., \& Bertenthal, B. I. (1990). Converging operations revisited: Assessing what infants perceive using discrimination measures. Perception and Psychophysics, 47, 1-11.

Quittner, A. L., Smith, L. B., Osberger, M. J., Mitchell, T. V., \& Katz, D. B. (1994). The impact of audition on the development of visual attention. Psychological Science, 5, 347-353.

Radell, P. L., \& Gottlieb, G. (1992). Developmental intersensory interference: Augmented prenatal sensory experience interferes with auditory learning in duck embryos. Developmental Psychology, 28, 795-803.

Reed, E. S. (1996). Encountering the world: Towards an ecological psychology. New York: Oxford University Press.

Richters, J. E. (1997). The Hubble hypothesis and the developmentalist's dilemma. Development and Psychopathology, 9, 193-229.

Robertson, S. S., \& Bacher, L. F. (1995). Oscillation and chaos in fetal motor activity. In J.-P. Lecanuet, W. P. Fifer, N. A. Krasnegor, \& W. P. Smotherman (Eds.), Fetal development: A psychobiological perspective (pp. 168-189). Hillsdale, NJ: Erlbaum.

Rochat, P. (1992). Self-sitting and reaching in 5- to 8-month-old infants: The impact of posture and its development on early eye-hand coordination. Journal of Motor Behavior, 24, 210-220.

Rochat, P. (Ed.). (1995). The self in infancy: Theory and research. Amsterdam: North-Holland-Elsevier.

Rochat, P., \& Morgan, R. (1995). Spatial determinants in the perception of self produced leg movements by 3 - to 5 -month old infants. Developmental Psychology, 31, 626-636.

Rochat, P., \& Senders, S. J. (1991). Active touch in infancy: Actions systems in development. In M. J. Weiss \& P. R. Zelazo (Eds.), Infant attention: Biological constraints and the influence of experience (pp. 412-442). Norwood, NJ: Ablex.

Roe, A. W., Pallas, S. L., Hahm, J. O., \& Sur, M. (1990, November 9). A map of visual space induced in primary auditory cortex. Science, 250, $818-820$

Rose, S. A. (1994). From hand to eye: Findings and issues in infant cross-modal transfer. In D. J. Lewkowicz \& R. Lickliter (Eds.), The development of intersensory perception: Comparative perspectives (pp. 265-284). Hillsdale, NJ: Erlbaum.

Rose, S. A., \& Ruff, H. A. (1987). Cross-modal abilities in human infants. In J. D. Osofsky (Ed.), Handbook of infant development (pp. 318-362). New York: Wiley.

Ryan, T. A. (1940). Interrelations of the sensory systems in perception. Psychological Bulletin, 37, 659-698.

Schaal, B., Marlier, L., \& Soussignan, R. (1998). Olfactory function in the 
human fetus: Evidence from selective neonatal responsiveness to the order of amniotic fluid. Behavioral Neuroscience, 112, 1-12.

Schaal, B., Orgeur, P., \& Arnould, C. (1995). Chemosensory preferences in newborn lambs: Prenatal and perinatal determinants. Behaviour, 132, 352-365.

Schanberg, S. M., \& Field, T. M. (1987). Sensory deprivation, stress and supplemental stimulation in the rat pup and preterm human neonate. Child Development, 58, 1431-1447.

Schmuckler, M. J. (1995). Self-knowledge of body position: Integration of perceptual and action system information. In P. Rochat (Ed.), The self in infancy: Theory and research (pp. 221-241). Amsterdam: NorthHolland-Elsevier.

Schmuckler, M. J. (1996). Visual-proprioceptive intermodal perception in infancy. Infant Behavior and Development, 19, 221-232.

Schneirla, T. C. (1959). An evolutionary and developmental theory of biphasic processes underlying approach/withdrawal. In M. Jones (Ed.), Nebraska symposium on motivation, Vol. 7 (pp. 1-42). Lincoln: University of Nebraska Press.

Schneirla, T. C. (1966). Behavioral development and comparative psychology. Quarterly Review of Biology, 41, 283-302.

Shillito, E. (1975). A comparison of the role of vision and hearing in lambs finding their own dams. Applied Animal Ethology, 1, 369-377.

Slater, A. (in press). Intermodal perception at birth: Intersensory redundancy guides newborns' learning of arbitrary auditory-visual pairings. British Journal of Developmental Psychology.

Sleigh, M. J., Columbus, R. F., \& Lickliter, R. (1996). Type of prenatal sensory experience affects prenatal auditory learning in bobwhite quail. Journal of Comparative Psychology, 110, 233-242.

Sleigh, M. J., Columbus, R. F., \& Lickliter, R. (1998). Intersensory experience and early perceptual development: Postnatal experience with multimodal maternal cues affects intersensory responsiveness in bobwhite quail chicks. Developmental Psychology, 34, 215-223.

Sleigh, M. J., \& Lickliter, R. (1995). Augmented prenatal visual stimulation alters postnatal auditory and visual responsiveness in bobwhite quail chicks. Developmental Psychobiology, 28, 353-366.

Sleigh, M. J., \& Lickliter, R. (1996). Type and amount of prenatal stimulation alters perceptual responsiveness in bobwhite quail chicks. Infant Behavior and Development, 19, 325-338.

Sleigh, M. J., \& Lickliter, R. (1997). Augmented prenatal auditory stimulation alters postnatal perception, arousal, and survival in bobwhite quail chicks. Developmental Psychobiology, 30, 201-212.

Sleigh, M. J., \& Lickliter, R. (1998). Timing of the presentation of prenatal auditory stimulation affects postnatal perceptual responsiveness in bobwhite quail chicks. Journal of Comparative Psychology, 112, 153-160.

Smith, L. B. (1994). Forward. In D. J. Lewkowicz \& R. Lickliter (Eds.), The development of intersensory perception: Comparative perspectives (pp. ix-xix). Hillsdale, NJ: Erlbaum.

Smotherman, W. P., \& Robinson, S. R. (1988). The uterus as environment: The ecology of fetal behavior. In E. M. Blass (Ed.), Handbook of behavioral neurobiology (Vol. 9, pp. 149-196). New York: Plenum.

Smotherman, W. P., \& Robinson, S. R. (1995). Tracing developmental trajectories into the prenatal period. In J.-P. Lecanuet, W. P. Fifer, N. A. Krasnegor, \& W. P. Smotherman (Eds.), Fetal development: A psychobiological perspective (pp. 15-32). Hillsdale, NJ: Erlbaum.

Spear, N. E. (1984). Ecologically determined dispositions control the ontogeny of learning and memory. In R. Kail \& N. E. Spear (Eds.) Comparative perspectives on the development of memory (pp. 227-252). Hillsdale, NJ: Erlbaum.

Spear, N. E., Kraemer, P. J., Molina, J. C., \& Smoller, D. (1988). Developmental change in learning and memory: Infantile disposition for "unitization." In J. Delacour \& J. C. Levy (Eds.), Systems with learning and memory abilities (pp. 27-52). Amsterdam: North-Holland-Elsevier.

Spear, N. E., \& Kucharski, D. (1984). Ontogenetic differences in the processing of multi-element stimuli: Potentiation and overshadowing. In
H. Roitblat, T. Bever, \& H. Terrace (Eds.), Animal cognition (pp. 545-567). Hillsdale, NJ: Erlbaum.

Spear, N. E., \& McKinzie, D. L. (1994). Intersensory integration in the infant rat. In D. J. Lewkowicz \& R. Lickliter (Eds.), The development of intersensory perception: Comparative perspectives (pp. 133-161). Hillsdale, NJ: Erlbaum.

Spelke, E. S. (1976). Infants' intermodal perception of events. Cognitive Psychology, 8, 553-560.

Spelke, E. S. (1979). Perceiving bimodally specified events in infancy. Developmental Psychology, 15, 626-636.

Spelke, E. S. (1981). The infant's acquisition of knowledge of bimodally specified events. Journal of Experimental Child Psychology, 31, 279299.

Spelke, E. S. (1984). The development of intermodal perception. In P. Salapatek \& L. B. Cohen (Eds.), Handbook of infant perception (pp. 233-273). New York: Academic Press.

Staddon, J. E. R. (1989). Animal psychology: The tyranny of anthropocentrism. In P. P. G. Bateson \& P. H. Klopfer (Eds.), Perspectives in ethology (Vol. 8, pp. 123-134). New York: Plenum.

Stein, B. E., \& Meredith, M. A. (1993). The merging of the senses. Cambridge, MA: MIT Press.

Stein, B. E., Meredith, M. A., Huneycutt, W. S., \& McDade, L. (1989). Behavioral indices of multisensory integration: Orientation to visual cues is affected by auditory stimuli. Joumal of Cognitive Neuroscience, 1, 12-24.

Stein, B. E., Meredith, M. A., \& Wallace, M. (1994). Development and neural basis of multisensory integration. In D. J. Lewkowicz \& R. Lickliter (Eds.), The development of intersensory perception: Comparative perspectives (pp. 81-105). Hillsdale, NJ: Erlbaum.

Stern, D. (1985). The interpersonal world of the infant. New York: Basic Books.

Streri, A. (1993). Seeing, reaching, touching: The relations between vision and touch in infancy. Cambridge, MA: MIT Press.

Streri, A., \& Molina, M. (1994). Constraints on intermodal transfer between touch and vision in infancy. In D. J. Lewkowicz \& R. Lickliter (Eds.), The development of intersensory perception: Comparative perspectives (pp. 285-307). Hillsdale, NJ: Erlbaum.

Streri, A., \& Pecheux, M.-G. (1986). Vision to touch and touch to vision transfer of form in 5-month-old infants. British Journal of Developmental Psychology, 4, 161-167.

Symons, L. A., \& Tees, R. C. (1990). An examination of the intramodal and intermodal behavioral consequences of long-term vibrissae removal in rats. Developmental Psychobiology, 23, 849-867.

Tees, R. C. (1994). Early stimulation history, the cortex, and intersensory functioning in infrahumans: Space and time. In D. J. Lewkowicz \& R. Lickliter (Eds.), The development of intersensory perception: Comparative perspectives (pp. 107-131). Hillsdale, NJ: Erlbaum.

Tees, R. C., \& Symons, L. A. (1987). Intersensory coordination and the effect of early sensory deprivation. Developmental Psychobiology, 23, 497-507.

Thelen, E., Corbetta, D., Kamm, K., Spencer, J., Schneider, K., \& Zernicke, R. F. (1993). The transitions to reaching: Mapping intention and intrinsic dynamics. Child Development, 64, 1058-1098.

Thelen, E., \& Smith, L. B. (1994). A dynamic systems approach to the development of cognition and action. Cambridge, MA: MIT Press.

Turkewitz, G. (1994). Sources of order for intersensory functioning. In D. J. Lewkowicz \& R. Lickliter (Eds.), The development of intersensory perception: Comparative perspectives (pp. 3-17). Hillsdale, NJ: Erlbaum.

Turkewitz, G., \& Devenny, D. A. (Eds.). (1993). Developmental time and timing. Hillsdale, NJ: Erlbaum.

Turkewitz, G., Gilbert, M., \& Birch, H. G. (1974). Early restriction of tactile stimulation and visual functioning in the kitten. Developmental Psychobiology, 7, 243-248. 
Turkewitz, G., \& Kenny, P. A. (1982). Limitations on input as a basis for neural organization and perceptual development: A preliminary theoretical statement. Developmental Psychobiology, 15, 357-368.

Turkewitz, G., \& Kenny, P. A. (1985). The role of developmental limitations of sensory input on sensory/perceptual organization. Journal of Developmental and Behavioral Pediatrics, 6, 302-306.

Turkewitz, G., Lewkowicz, D. J., \& Gardner, J. M. (1983). Determinants of infant perception. In J. S. Rosenblatt, R. A. Hinde, C. Beer, \& M. C. Busnel (Eds.), Advances in the study of behavior (Vol. 13, pp. 39-62). New York: Academic Press.

Turkewitz, G., \& McGuire, I. (1978). Intersensory functioning during early development. International Journal of Mental Health, 7, 165-182.

Turkewitz, G., \& Mellon, R. C. (1989). Dynamic organization of intersensory function. Canadian Journal of Psychology, 43, 286-301.

Valsiner, J. (1987). Culture and the development of children's action. New York: Wiley.

Valsiner, J. (1998). The guided mind. Cambridge, MA: Harvard University Press.

Van der Meer, A. L., \& Van der Weel, F. (1995). Move yourself, baby! Percepto-motor development from a continuous perspective. In P. Rochat (Ed.), The self in infancy: Theory and research (pp. 257-276). Amsterdam: North-Holland-Elsevier.

von Uexkull, J. (1957). A stroll through the world of animals and men. In C. H. Schiller (Ed.), Instinctive behavior (pp. 5-80). New York: International Universities Press.

Walker-Andrews, A. S. (1986). Intermodal perception of expressive behaviors: Relation of eye and voice? Developmental Psychology, 22, 373-377.

Walker-Andrews, A. S. (1994). Taxonomy for intermodal relations. In D. J. Lewkowicz \& R. Lickliter (Eds.), The development of intersensory perception: Comparative perspectives (pp. 39-56). Hillsdale, NJ: Erlbaum.
Walker-Andrews, A. S. (1997). Infants' perception of expressive behavior: Differentiation of multimodal information. Psychological Bulletin, 121, 437-456.

Walker-Andrews, A. S., Bahrick, L. E., Raglioni, S. S., \& Diaz, I. (1991). Infants' bimodal perception of gender. Ecological Psychology, 3, 55-75.

Wallace, M., \& Stein, B. E. (1997). Development of multisensory neurons and multisensory integration in cat superior colliculus. Journal of $\mathrm{Neu}$ roscience, 17, 2429-2444.

Werker, J. F., \& McLeod, P. J. (1989). Infant preference for both male and female infant-directed talk: A developmental study of attentional and affective responsiveness. Canadian Journal of Psychology, 43, 230246.

Werner, H. (1957). The concept of development from a comparative and organismic point of view. In D. B. Harris (Ed.), The concept of development (pp. 125-148). Minneapolis: University of Minnesota Press.

Withington-Wray, D. J., Binns, K. E., \& Keating, M. J. (1990). The maturation of the superior collicular map of auditory space in the guinea pig is disrupted by developmental visual deprivation. European Journal of Neuroscience, 2, 682-692.

Wozniak, R. H., \& Fischer, K. W. (1993). Development in context: Acting and thinking in specific environments. Hillsdale, $\mathrm{NJ}$ : Erlbaum.

Zukow-Goldring, P. (1997). A social ecological realist approach to the emergence of the lexicon: Educating attention to amodal invariants in gesture and speech. In C. Dent-Read \& P. Zukow-Goldring (Eds.), Evolving explanations of development (pp. 199-249). Washington, DC: American Psychological Association.

Received May 22, 1998

Revision received October 13, 1999

Accepted October 13, 1999 